\title{
Article \\ In Silico, In Vitro and In Vivo Analysis of Tanshinone IIA and Cryptotanshinone from Salvia miltiorrhiza as Modulators of Cyclooxygenase-2/mPGES-1/Endothelial Prostaglandin EP3 Pathway
}

\author{
Anella Saviano ${ }^{1,+}$, Simona De Vita ${ }^{2,+} \mathbb{D}$, Maria Giovanna Chini ${ }^{3}$, Noemi Marigliano ${ }^{1}$, Gianluigi Lauro ${ }^{2} \mathbb{D}$, \\ Gian Marco Casillo ${ }^{1}$, Federica Raucci ${ }^{1}$, Maria Iorizzi ${ }^{3}{ }^{1}$, Robert Klaus Hofstetter $^{4}$, Katrin Fischer ${ }^{4}$, \\ Andreas Koeberle $^{5}\left(\mathbb{D}\right.$, Oliver Werz ${ }^{4}\left(\mathbb{D}\right.$, Francesco Maione ${ }^{1, *} \mathbb{D}$ and Giuseppe Bifulco ${ }^{2, *}$
}

check for

updates

Citation: Saviano, A.; De Vita, S.; Chini, M.G.; Marigliano, N.; Lauro, G.; Casillo, G.M.; Raucci, F.; Iorizzi, M.; Hofstetter, R.K.; Fischer, K.; et al. In Silico, In Vitro and In Vivo Analysis of Tanshinone IIA and Cryptotanshinone from Salvia miltiorrhiza as Modulators of Cyclooxygenase-2/mPGES-1/ Endothelial Prostaglandin EP3 Pathway. Biomolecules 2022, 12, 99. https://doi.org/10.3390/ biom12010099

Academic Editors: Vladimir N. Uversky and Antonio Evidente

Received: 3 December 2021

Accepted: 3 January 2022

Published: 7 January 2022

Publisher's Note: MDPI stays neutral with regard to jurisdictional claims in published maps and institutional affiliations.

Copyright: (C) 2022 by the authors. Licensee MDPI, Basel, Switzerland. This article is an open access article distributed under the terms and conditions of the Creative Commons Attribution (CC BY) license (https:// creativecommons.org/licenses/by/ $4.0 /)$.
1 ImmunoPharmaLab, Department of Pharmacy, School of Medicine and Surgery, University of Naples Federico II, Via Domenico Montesano 49, 80131 Naples, Italy; nella.1993@hotmail.it (A.S.); noemi.marigliano@outlook.com (N.M.); gianmarcocasillo@virgilio.it (G.M.C.); federica.raucci@unina.it (F.R.)

2 Department of Pharmacy, University of Salerno, Via Giovanni Paolo II 132, 84084 Fisciano, Italy; sdevita@unisa.it (S.D.V.); glauro@unisa.it (G.L.)

3 Department of Biosciences and Territory, University of Molise, Contrada Fonte Lappone, Pesche, 86090 Isernia, Italy; mariagiovanna.chini@unimol.it (M.G.C.); iorizzi@unimol.it (M.I.)

4 Department of Pharmaceutical/Medicinal Chemistry, Institute of Pharmacy, Friedrich-Schiller-University Jena, Philosophenweg 14, 07743 Jena, Germany; robert.klaus.hofstetter@uni-jena.de (R.K.H.); katrin.fischer.1@uni-jena.de (K.F.); oliver.werz@uni-jena.de (O.W.)

5 Michael Popp Institute, University of Innsbruck, Mitterweg 24, 6020 Innsbruck, Austria; Andreas.Koeberle@uibk.ac.at

* Correspondence: francesco.maione@unina.it (F.M.); bifulco@unisa.it (G.B.); Tel.: +39-081678429 (F.M.); +39-089969741 (G.B.)

+ These authors contributed equally to this work.

\begin{abstract}
Tanshinone IIA (TIIA) and cryptotanshinone (CRY) from Salvia miltiorrhiza Bunge were investigated for their inhibitory activity against the cyclooxygenase-2 (COX-2)/microsomal prostaglandin E synthase-1 (mPGES-1)/endothelial prostaglandin 3 (EP3) pathway using in silico, in vitro, in vivo, and ex vivo assays. From the analysis of the docking poses, both diterpenoids were able to interact significantly with COX-2, 5-lipoxygenase (5-LO), platelet-activating factor receptor (PAFR), and mPGES-1. This evidence was further corroborated by data obtained from a cell-free assay, where CRY displayed a significant inhibitory potency against mPGES-1 $\left(\mathrm{IC}_{50}=1.9 \pm 0.4 \mu \mathrm{M}\right)$ and 5-LO $\left(\mathrm{IC}_{50}=7.1 \mu \mathrm{M}\right)$, while TIIA showed no relevant inhibition of these targets. This was consistent with their activity to increase mice bleeding time (CRY: $2.44 \pm 0.13 \mathrm{~min}, p \leq 0.001$; TIIA: $2.07 \pm 0.17 \mathrm{~min}$ $p \leq 0.01$ ) and with the capability to modulate mouse clot retraction (CRY: $0.048 \pm 0.011 \mathrm{~g}, p \leq 0.01$; TIIA: $0.068 \pm 0.009 \mathrm{~g}, p \leq 0.05$ ). For the first time, our results show that TIIA and, in particular, CRY are able to interact significantly with the key proteins involved not only in the onset of inflammation but also in platelet activity (and hyper-reactivity). Future preclinical and clinical investigations, together with this evidence, could provide the scientific basis to consider these compounds as an alternative therapeutic approach for thrombotic- and thromboembolic-based diseases.
\end{abstract}

Keywords: docking; EPs; mPGES-1; platelet aggregation; tanshinones

\section{Introduction}

Inflammation is a complex defense mechanism characterized by leukocyte extravasation from the vasculature to local tissue damage due to injurious and noxious agents / stimuli $[1,2]$. Neutrophils dominate the initial influx of leukocytes, followed by monocytes and macrophages. These events are correlated with a transient increase of proinflammatory mediators, including cytokines, chemokines, prostaglandins (PGs), and 
leukotrienes (LTs) [3-5]. Moreover, the development of inflammatory conditions is often associated with cardiovascular alterations of platelet activity (and hyper-reactivity) and, to a lesser extent, thrombotic and thromboembolic complications [6-8].

PGs and LTs are powerful bioactive lipid mediators that are involved in the onset of inflammation and in numerous homeostatic functions $[9,10]$. The biosynthesis of PGs is initialized by cyclooxygenases (COXs) isoenzymes (COX-1 and COX-2) that convert arachidonic acid to $\mathrm{PGH}_{2}$ [11], which is subsequently isomerized to prostaglandin (PG) $\mathrm{E}_{2}$ by three different $\mathrm{PGE}_{2}$ synthases situated downstream of the COXs [12]. The cytosolic prostaglandin $\mathrm{E}_{2}$ synthase (cPGES) and the microsomal prostaglandin $\mathrm{E}_{2}$ synthase (mPGES)-2 are constitutive enzymes, whereas mPGES-1 is an inducible isoform [13-15]. Consistently, the upregulation of mPGES-1 expression and the involvement of the COX2/mPGES-1/PGE 2 cascade in terms of PGs production has been extensively reported in pathological settings in which $\mathrm{PGE}_{2}$ is implicated, such as fever, pain, and inflammatorybased disease [16-18].

Several lines of evidence also indicate that mPGES- 1 activity is detrimental for platelet aggregation [19-21], thrombosis, and hemostasis [22-24] and that $\mathrm{PGE}_{2}$, thromboxane (TXA), and matrix metalloproteinase (MMPs) are expressed on platelets in both resting and activating conditions [25-27].

$\mathrm{PGE}_{2}$ acts on four specific G-protein-coupled receptors (GPCR) subtypes, named endothelial prostaglandin 1-4 (EP1-4), mediating different biological functions, and exhibiting a biphasic effect on platelet aggregation [28]. Specifically, EP2, EP3, and EP4 are all expressed on platelets, and the expression level of EP3 is much higher than EP2 and EP4. Functionally, EP3 mediates the pro-aggregatory effect of $\mathrm{PGE}_{2}$-dependent [29-31]; whereas EP2 and EP4 signaling mediate anti-aggregatory effects.

Considerable interest has been expressed in natural products and their bioactive components that exert antiplatelet activities to reduce thrombotic risk and related cardiovascular complications [32-34]. In this context, tanshinone IIA (TIIA) and cryptotanshinone (CRY), the main lipophilic components from the rhizome of Salvia miltiorrhiza Bunge, have been widely used for the effective treatment of atherothrombosis in traditional Chinese medicine (Figure 1) [35,36].

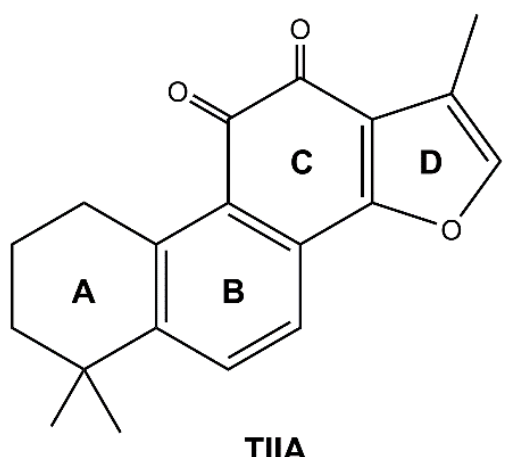

TIIA

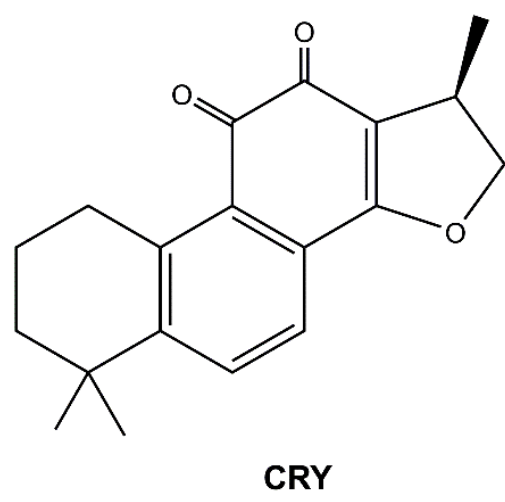

Figure 1. Chemical structure of TIIA and CRY.

Until now, the molecular mechanisms of action of these two diterpenoids on platelets are only partially known. We have previously demonstrated that TIIA and CRY are able to inhibit rat platelet aggregation via the modulation of tubulin acetylation and the inhibition of extracellular signal-regulated kinases-2 (ERK-2) phosphorylation [37] and that their effects were mediated by the interaction with the $\mathrm{G}_{\mathrm{i}}$-coupled P2Y12 receptor [38]. On these bases, their role on key targets involved in thrombogenic processes was investigated using a combined in silico, in vitro, in vivo, and ex-vivo approach to provide further insights into the biological activities of these natural compounds. 


\section{Materials and Methods}

\subsection{Computational Details}

2.1.1. Input File Preparation

The chemical structures of TIIA and CRY were built using the graphical interface of the Schrödinger Suite [39] and processed with LigPrep [40] to adjust the partial charges and the protonation state of the compounds. The following structures were collected from the Protein Data Bank [41]: secreted phospholipase $\mathrm{A}_{2}$ (sPLA 2 ) (PDB: 3U8H [42]), COX-1 (PDB ID: 3KK6 [43]), COX-2 (PDB ID: 5KIR [44]), 5-lipoxygenase (5-LO) (PDB ID: 3O8Y [45]), mPGES-1 (PDB ID: 5K0I [46]), platelet-activating factor receptor (PAFR) (PDB ID: 5ZKQ [47]), EP3 (PDB ID: 6AK3 [48]), EP4 (PDB ID: 5YWY [49]), MMP-1 (PDB ID: 966C [50]), MMP2 (PDB ID: 1HOV [51]). The structures were prepared with the Protein Preparation Wizard [52,53], which determines the protonation state of each atom, adjusts the bond orders, and optimizes the intramolecular hydrogen bond network. The centroid of each ligand (where available) was used as a guide to build the necessary molecular docking grid. Due to the lack of a co-crystallized molecule in the 5-LO structure, the protocol illustrated in previous work [54] was followed. In detail, the centroid of key binding site residues (Phe177, Tyr181, His367, Leu368, His372, Leu373, Ile406, Leu414, His550, Asn554, Leu607, Ile673) was considered as the center and the inner box was extended for $10 \AA$ and the outer box for $20 \AA$ in the three spatial dimensions.

\subsubsection{Molecular Docking}

For all the targets considered, except for 5-LO, a semiflexible molecular docking approach was followed using the software Glide [55-58] in Extra Precision (XP) mode. In detail, 10,000 poses were initially generated for each ligand and evaluated to select 800 conformations to enter the minimization step with an energetic cutoff of $0.15 \mathrm{kcal} / \mathrm{mol}$. After that, a maximum of 15 poses was kept for each ligand for the visual inspection.

Concerning 5-LO, an Induced Fit approach [59-62] was used to mimic the high flexibility of the binding pocket residues [63]. We used the extended sampling protocol keeping all the residues flexible within $5 \AA$ from the ligand and generating up to 80 poses for each molecule.

\subsection{Cell-Free mPGES-1 Activity Assay}

A549 cells were cultured and treated as described elsewhere [64,65]. In brief, to induce the expression of mPGES-1, cells were incubated for $72 \mathrm{~h}$ with $1 \mathrm{ng} / \mathrm{mL}$ of interleukin- $1 \beta$ (IL-1 $\beta$ ). Afterward, cells were harvested with trypsin/EDTA, collected, sonicated, and centrifuged at $4{ }^{\circ} \mathrm{C}$ at $10,000 \times g$ for $10 \mathrm{~min}$ and then at $174,000 \times g$ for $1 \mathrm{~h}$. The pellet containing the microsomal fraction was resuspended in $1 \mathrm{~mL}$ of buffer containing $0.1 \mathrm{M}$ potassium phosphate buffer ( $\mathrm{pH} 7.4$ ), $1 \mathrm{mM}$ phenylmethanesulfonyl fluoride, $60 \mu \mathrm{g} / \mathrm{mL}$ soybean trypsin inhibitor, $1 \mu \mathrm{g} / \mathrm{mL}$ leupeptin, $2.5 \mathrm{mM}$ glutathione (GSH), and $250 \mathrm{mM}$ sucrose. After the protein concentration was determined, the fraction was diluted in phosphate buffer 1.0 M (pH 7.4) with the addition of $2.5 \mathrm{mM} \mathrm{GSH}$. The compounds and DMSO (as control) were added to the microsomal fraction and incubated for 15 min at $4{ }^{\circ} \mathrm{C}$. The addition of $20 \mu \mathrm{M} \mathrm{PGH} 2$ started the enzymatic conversion, which was stopped after $1 \mathrm{~min}$ by adding $100 \mu \mathrm{L}$ of stop solution $\left(40 \mathrm{mM} \mathrm{FeCl} \mathrm{m}_{2}, 80 \mathrm{mM}\right.$ citric acid, and $10 \mu \mathrm{M}$ RP-HPLC $\left.11 \beta-\mathrm{PGE}_{2}\right)$. The $\mathrm{PGE}_{2}$ produced was extracted by solid-phase extraction and analyzed with RP-HPLC.

\subsection{Cell-Free 5-LO, COX-1 and COX-2 Assays}

5-LO was expressed in E. coli BL21 (DE3) transformed with the pT3-5-LO plasmid and purified by affinity chromatography on an ATP-agarose column [66]. The isolated enzyme was used immediately for 5-LO activity assays as described in detail in [67]. Briefly, $0.5 \mu \mathrm{g}$ of 5-LO in PBS pH 7.4 containing EDTA $(1 \mathrm{mM})$ were pre-incubated with TIIA, CRY, or vehicle (0.1\% DMSO). After $15 \mathrm{~min}$, samples were pre-warmed for $30 \mathrm{~s}$ at $37^{\circ} \mathrm{C}$ before adding $2 \mathrm{mM} \mathrm{CaCl} 2$ plus $20 \mu \mathrm{M}$ AA to start 5-LO product formation. After $10 \mathrm{~min}$ 
at $37^{\circ} \mathrm{C}$, an equal volume of ice-cold methanol was added to quench the reaction, and the formed 5-LO products were extracted by adding $500 \mu \mathrm{L}$ acidified PBS and $200 \mathrm{ng}$ of internal $\mathrm{PGB}_{1}$ standard before solid-phase extraction. Eluates were analyzed for 5-LO products (tr-LTB 4 and 5-H(P)ETE) by RP-HPLC using a C-18 Radial-PAK column (Waters, Eschborn, Germany).

COXs inhibition was assayed using purified ovine COX-1 and recombinant human COX-2 as described in [68]. Briefly, COX-1 $(50 \mathrm{U} / \mathrm{mL})$ or COX-2 $(20 \mathrm{U} / \mathrm{mL})$ were diluted in Tris buffer (100 mM, pH 8) containing glutathione (5 mM), EDTA (100 $\mu \mathrm{M})$, and hemoglobin $(5 \mu \mathrm{M})$. After pre-incubation with TIIA, CRY, or vehicle (0.1\% DMSO) for $5 \mathrm{~min}$ at room temperature (RT), the samples were pre-warmed for $30 \mathrm{sec}$ at $37^{\circ} \mathrm{C}$, and the reactions were started with $5 \mu \mathrm{M}$ AA (COX-1) or $2 \mu \mathrm{M}$ AA (COX-2). After $5 \mathrm{~min}$ at $37^{\circ} \mathrm{C}$, the reactions were stopped by the addition of an equal volume of ice-cold methanol. Solid-phase extraction was performed as described above, and COXs product formation was determined by analysis of 12-hydroxyheptadecatrienoic acid (12-HHT) formation.

\subsection{Materials}

TIIA, CRY ( $\geq 97 \%$ and $\geq 98 \%$, respectively, HPLC), and acetylsalicylic acid (ASA) were obtained from Sigma-Aldrich Co. (Milan, Italy). For western blot analysis, anti-PTGER2 was obtained from Origene (Rockville, MD, USA), anti-PTGER3 and anti-PTGER4 from Proteintech (Manchester, UK), and anti-alpha tubulin from SICGEN (Cantanhede, Portugal). HRP-conjugated IgG secondary antibodies were purchased from Dako (Copenhagen, Denmark). Unless otherwise stated, all the other reagents were from BioCell (Milan, Italy).

\subsection{Animals}

CD-1 male mice (12 weeks of age) were purchased from Charles River (Milan, Italy) and kept in an animal care facility under controlled temperature, humidity, and on a 12/12 light: dark cycle, with ad libitum access to water and a standard laboratory chow diet. All animal care and experimental procedures complied with the international and national law and policies and were approved (authorization number: 545/2021-PR) by the Italian Ministry of Health (EU Directive 2010/63/EU for animal experiments, and the Basel declaration including the $3 \mathrm{Rs}$ concept) $[69,70]$. All procedures were carried out to minimize the number of animals used ( $n=7$ per group) and their suffering.

\subsection{In Vivo Bleeding Time}

For the in vivo model, a well-established method of bleeding time was used [71]. Mice were anesthetized intraperitoneally (i.p.) with a mixture of ketamine $(75 \mathrm{mg} / \mathrm{kg})$ and xylazine $(10 \mathrm{mg} / \mathrm{kg})$, and the tail was pre-warmed for $3 \mathrm{~min}$ in a $0.9 \%$ saline solution at $37^{\circ} \mathrm{C}$ $1 \mathrm{~h}$ after the i.p. injection of TIIA and CRY (both at the dose of $10 \mathrm{mg} / \mathrm{kg})$, ASA $(10 \mathrm{mg} / \mathrm{kg})$, and their vehicles (8\% methanol in saline and 1\% CMC in saline, for tanshinones and ASA, respectively). The bleeding was induced by a precise incision of the mouse tail $5 \mathrm{~mm}$ from the tip. The distal portion of the tail $(3 \mathrm{~cm})$ was immersed vertically into the $0.9 \%$ saline solution at $37^{\circ} \mathrm{C}$. Blood flowing from the incision was carefully monitored, and the time to cessation of bleeding was recorded as the bleeding time. Bleeding cessation was the time when the flow of blood stopped.

\subsection{Ex Vivo Clot Retraction}

The protocol proposed by Law et al. with slight modifications was adopted [72]. Briefly, non-anticoagulated blood samples, obtained by intracardiac puncture $(300 \mu \mathrm{L})$ were transferred into a Microvette ${ }^{\circledR} 300 \mathrm{Z}$ (Sarstedt, Verona, Italy) containing a clotting activator and incubated at room temperature for $2 \mathrm{~h}$ to get clot formation. Thereafter, clots were collected and weighed $(\mathrm{g})$, and residual serum volumes $(\mu \mathrm{L})$ were pipetted as an indirect value of reaction [73]. 


\subsection{Western Blot Analysis}

Whole clots, previously homogenated, were subjected to SDS-PAGE (10\% gel) using standard protocols as previously described $[74,75]$. The proteins $(35 \mu \mathrm{g})$ were transferred to nitrocellulose membrane $\left(0.2 \mu \mathrm{m}\right.$ nitrocellulose membrane, Trans-Blot ${ }^{\circledR}$ TurboTM, Transfer Pack, Bio-Rad Laboratories, Hercules, CA, USA) in the transfer buffer ( $25 \mathrm{mM}$ Tris- $\mathrm{HCl}$ (pH 7.4) containing $192 \mathrm{mM}$ glycine and 20\% v/v methanol) at $400 \mathrm{~mA}$ for $2 \mathrm{~h}$. The membranes were saturated by incubation for $2 \mathrm{~h}$ at RT with non-fat dry milk $(5 \% w / v)$ in PBS supplemented with $0.1 \%(v / v)$ Tween 20 (PBS-T), and then incubated with 1:1000 dilution of primary antibodies overnight at $4{ }^{\circ} \mathrm{C}$ with rabbit polyclonal anti-PTGER2 (TA351556), rabbit polyclonal anti-PTGER3 (24761-I-AP), rabbit polyclonal anti-PTGER4 (66921-1-Ig), goat polyclonal anti- alpha tubulin (AB0134-200), and then washed 3 times with PBS-T. In all cases, blots were then incubated with a 1:3000 dilution of related horseradish peroxidase-conjugated secondary antibody for $2 \mathrm{~h}$ at RT and finally washed 3 times with PBS-T. Protein bands were detected by using the enhanced chemiluminescence method (ClarityTM Western ECL Substrate, Bio-Rad Laboratories, Hercules, CA, USA) and Image Quant 400 GE Healthcare software (GE Healthcare, Milan, Italy). Finally, protein bands were quantified using the GS 800 imaging densitometer software (Biorad, Milan, Italy) and normalized with respective tubulin.

\subsection{Data and Statistical Analysis}

The data and statistical analysis in this study comply with the international recommendations on experimental design and analysis in pharmacology [76] and data sharing and presentation in preclinical pharmacology $[77,78]$. The results obtained were expressed as the mean \pm SD. Statistical analyses were performed by using one- or two-way ANOVA followed by Bonferroni testing when comparing more than two groups. GraphPad Prism 8.0 software (San Diego, CA, USA) was used for analysis. Data were considered statistically significant when a value of $p \leq 0.05$ was achieved.

\section{Results}

\subsection{Molecular Docking}

The chemical structure of the secondary metabolites considered in this work is reported in Figure 1. Both these lipophilic compounds are diterpenoid containing a tetrahydronaphthalene moiety (rings A and B) fused to an ortho-quinone (ring C) and a furan or dihydrofuran (ring D) for TIIA and CRY, respectively [79]. The small difference in ring D between the two secondary metabolites makes the TIIA structure planar and rigid, preventing the ring from bending to accommodate inside the pocket, and form additional interactions similar to COX-2, and MMP-2 (vide infra).

The first step to hypothesize a potential anti-inflammatory and/or anti-aggregant activity of the two tanshinones, TIIA and CRY, was performing molecular docking experiments on some relevant targets involved in these pathways. For this purpose, the following proteins were selected: sPLA 2 , COX-1, COX-2, 5-LO, mPGES-1, EP3, EP4, PAFR, MMP-1, and MMP-2 (Figure 2).

The structures were downloaded from the Protein Data Bank (https: / /www.rcsb.org/, accessed on 8 June 2020) [41,80] and cleaned from unnecessary elements like solvent molecules, ions, etc. Then, the proteins were prepared using the Protein Preparation Wizard [81], which corrects common structural errors in the protein (bond orders, protonation states, partial charges, etc.) and optimizes the intramolecular hydrogen bond network. Except for 5-LO, for which the procedures illustrated elsewhere were followed [82], all the proteins contained a co-crystallized molecule that was used to build the necessary grids for the subsequent molecular docking experiments. With this aim, the software Glide [55-58] was employed, and the resulting poses were visually inspected to determine the efficiency of the protein-ligand interactions. Moreover, a re-docking of the co-crystallized ligand was carried out to provide an energetic benchmark to estimate the binding of the two natural 
products; the chosen poses with the corresponding RMSD values from the co-crystallized ligand are reported in Figure S5 (Supplementary Material).

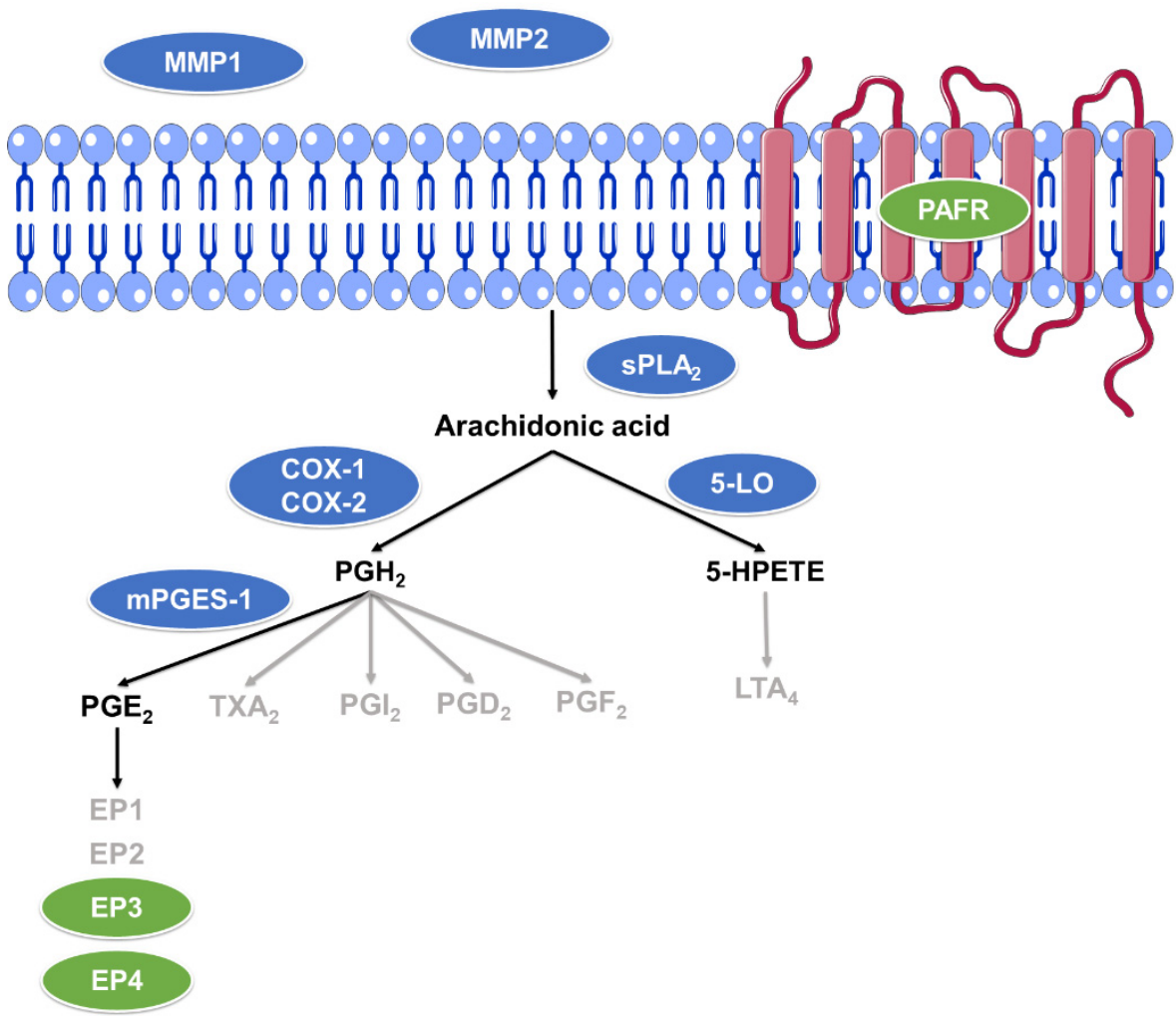

Figure 2. Inflammatory and aggregation pathways analyzed in this work. The elements excluded from the analysis are in gray, enzymes are enclosed in blue ovals, and receptors in green.

Based on the interactions made by the co-crystallized molecule and the information available [47-51,82-91], a set of key residues was identified for each target (Table 1). For the Ballesteros-Weinstein numbering scheme of PAFR, EP3, and EP4 please refer to Supporting Information.

Table 1. Important binding site residues for each target. For mPGES-1, the different chains are reported in brackets.

\begin{tabular}{cc}
\hline \multicolumn{1}{c}{ Protein } & Binding Site Residues \\
\hline sPLA $2[87,88]$ & Phe5, His6, Arg7, Lys10, Gly29, His47, Asp48, Lys61, Asp89, Phe93, \\
Phe98, His115, Arg117, and Arg122
\end{tabular}


Table 1. Cont.

\begin{tabular}{|c|c|}
\hline Protein & Binding Site Residues \\
\hline PAFR [47] & $\begin{array}{c}\text { Tyr22, Trp73, Tyr77, Phe97, Phe98, Thr101, Tyr102, Phe152, Glu175, } \\
\text { Tyr177, His188, Ile191, His248, Gln252, Trp255, His275, Leu279, } \\
\text { and Leu282 }\end{array}$ \\
\hline EP3 [48] & $\begin{array}{c}\text { Pro55, Met58, Asp99, Gln103, Thr106, Thr107, Val110, Tyr114, Met137, } \\
\text { Thr206, Trp207, Phe209, Trp295, Leu298, Leu329, Val332, Arg333, } \\
\text { Ser336, and Gln339, }\end{array}$ \\
\hline EP4 [49] & $\begin{array}{c}\text { Pro24, Val72, Thr76, Tyr80, Leu99, Thr168, Trp169, Leu312, Ile315, } \\
\text { Arg316, Ser319, and Val320 }\end{array}$ \\
\hline MMP-1 $[50,83]$ & $\begin{array}{c}\text { Arg114, Val115, His118, Glu119, Leu135, Tyr137, Phe138, Ser139, Tyr140, } \\
\text { Asn180, Leu181, Ala182, His183, and Glu219 }\end{array}$ \\
\hline MMP-2 [51] & $\begin{array}{l}\text { Leu82, Leu83, Ala84, His85, Leu116, Val117, His120, Leu137, Ala139, } \\
\text { Pro140, Ile141, Tyr142, Thr143, Thr145, and Leu150 }\end{array}$ \\
\hline
\end{tabular}

From the analysis of the molecular docking poses, some interesting data emerged. For CRY, 5-LO and PAFR were the targets that showed the best results, in terms of binding affinity and number of interactions with the key residues (listed in Table 1). In the remaining cases, the two molecules showed comparable results except for COX-2 and EP3, where CRY performed slightly better than the counterpart, probably due to the higher mobility of the methyl moiety on ring $\mathrm{D}$ that favors its accommodation in the binding pocket instead of keeping it in a rigid position (Figure 3). A detailed analysis of the molecular docking results is reported below.

Co-crystallized binding affinity

Co-crystallized interactions
TIIA binding affinity

TIIA interactions
CRY binding affinity

CRY interactions

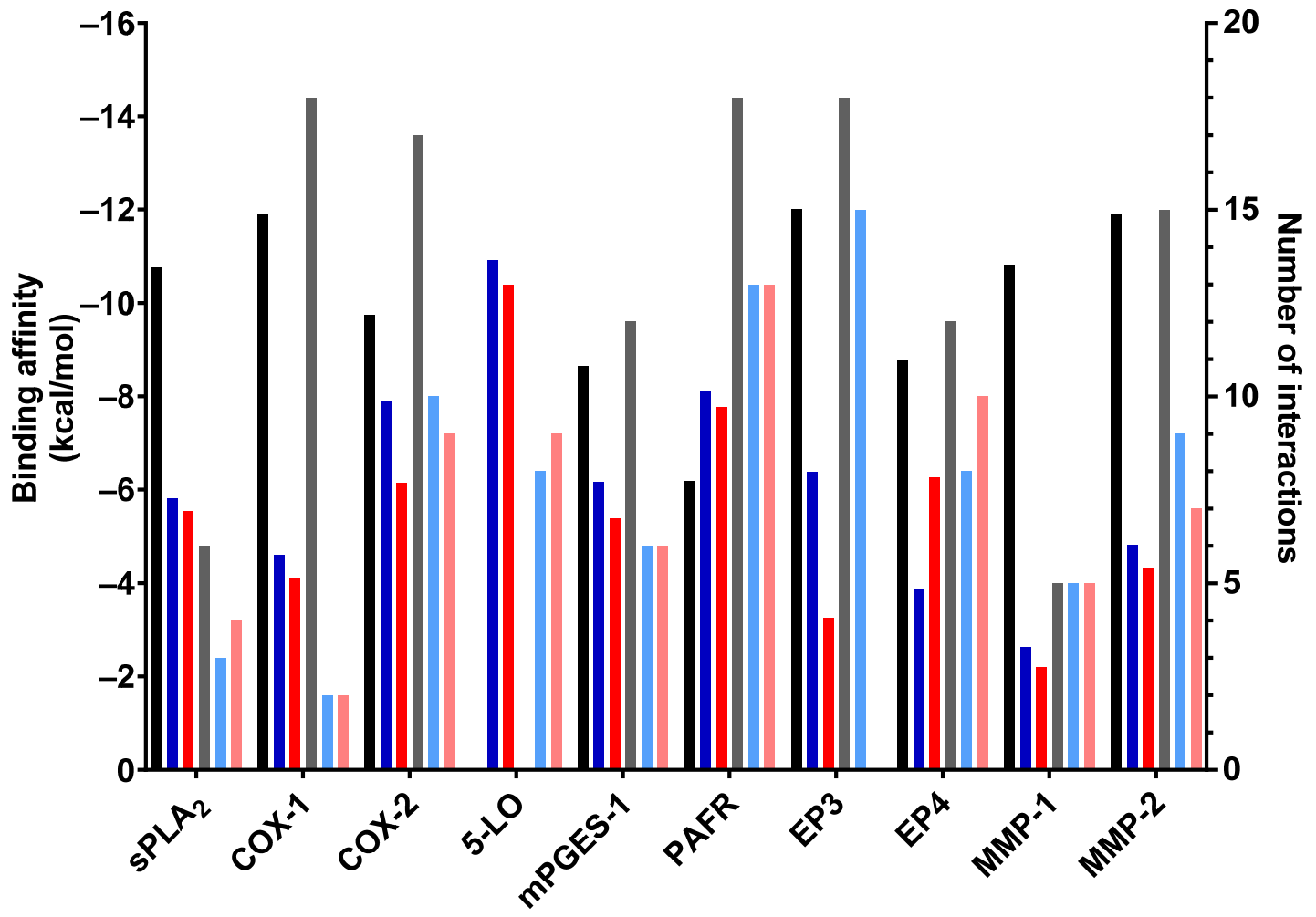

Figure 3. Binding energy and number of interactions made by the co-crystallized ligand (if available), TIIA, and CRY with each target. 


\subsection{1. $\mathrm{sPLA}_{2}$}

The sPLA $\mathrm{A}_{2}$ hydrolyzes arachidonic acid contained in the cell membrane, making it available to be transformed into a wide range of lipid mediators. It is a $\mathrm{Ca}^{2+}$-dependent enzyme, and the cation is responsible for the coordination of the glycerophospholipids before hydrolyzation [92]. The catalytic triad is represented by His47, Asp48, Asp89, and the $\mathrm{Ca}^{2+}$ ion [93]; the latter, though, is not strictly required for the binding of inhibitors [92]. Other important residues are those forming the hydrophobic cavity: Ile2, Leu5, Ala6, Val9, Pro17, Ile18, and Met21 [87].

Both compounds showed promising binding to the key amino acids highlighted above (Table 1), with very small differences in the calculated affinity and the three-dimensional arrangement inside the pocket. In detail, they form interactions with Gly29 (double hydrogen bond with the carbonyl groups) and His47 ( $\pi-\pi$ stacking), which are part of the catalytic triad, and additional contacts with Phe5 (both) and Tyr51 (only TIIA). Moreover, the lipophilic moiety is in perfect contact with the hydrophobic cavity surface (Figure 4). These considerations suggested the biological effect of these molecules on sPLA 2 .
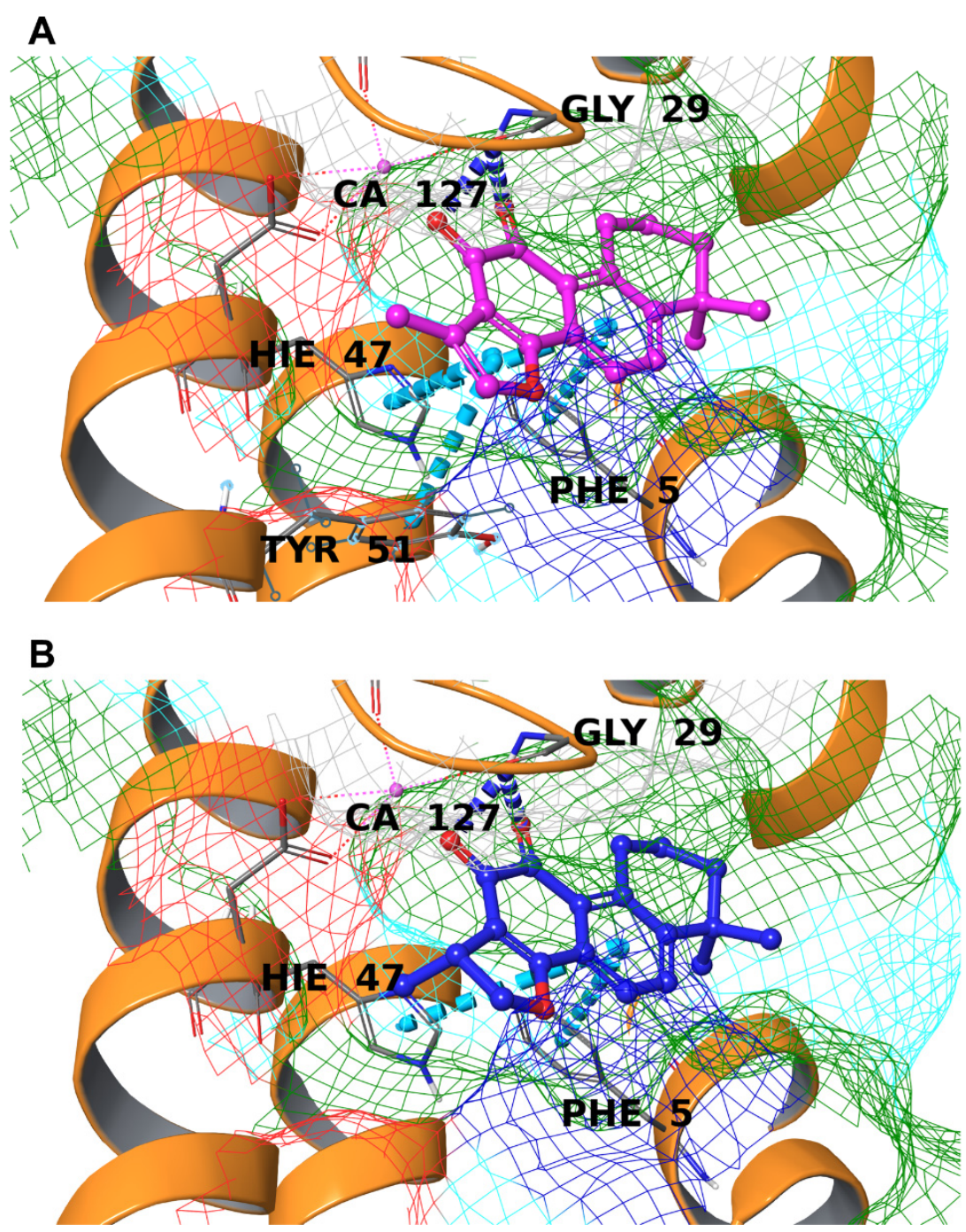

Figure 4. Binding mode of TIIA (A) and CRY (B) in the binding pocket of sPLA 2 . Hydrogen bonds are depicted as blue dotted lines, $\pi-\pi$ stackings are represented as cyan dotted lines, and the calcium atom is represented as a fuchsia sphere and labeled. The molecular surface of the binding site is shown and colored according to residue property: green for hydrophobic residues, cyan for polar ones, blue for positively charged amino acids, and red for negatively charged ones. The interacting residues are labeled in black with HIE representing the $\varepsilon$-nitrogen protonated histidine residue. 


\subsubsection{COX-1 and COX-2}

The substrate/inhibitor binding sites of COX-1 and COX-2 are notoriously very similar, with only an Ile/Val substitution in position 523 [94]. Each monomer consists of three different domains: the epidermal growth factor (EGF) domain, the membrane-binding domain, and the catalytic domain containing the catalytic triad Arg120, Tyr355, and Glu524. Among these domains, the catalytic triad represents the main target for non-steroidal anti-inflammatory drugs (NSAID) [95] and, particularly, Arg120, Tyr355, Tyr385, and Arg513 are essential for inhibitory activity $[95,96]$. The two co-crystallized molecules (celecoxib and rofecoxib, respectively, for COX-1 and COX-2) form a high number of interactions with the target due to their chemical structure, reflecting their excellent biological performance $[97,98]$.

The binding mode of TIIA and CRY was very similar in the case of COX-1; they both form a double hydrogen bond with Arg83 and make hydrophobic connections with Leu93 and Val119 (Figure 5A,B). Both molecules were inserted well in the binding site (delimited by a mesh colored according to the residue property) and made several contacts with the extended hydrophobic surface. Concerning COX-2, CRY formed a hydrogen bond with Tyr355 that, as mentioned above, is one of the key residues involved in the inhibition of this enzyme (Figure 5D), while TIIA interacted with the binding site only by hydrophobic contacts (Figure 5C), explaining the better predicted binding affinity of CRY with respect to TIIA. This difference between the two targets was due to the opposite binding pose of TIIA with respect to CRY (Figure 5E). The two ligands were almost superposed in the COX-1 binding site while their binding mode is the opposite in the case of COX-2, allowing only the carbonyl group of CRY to form a hydrogen bond with the $\mathrm{OH}$ group of Tyr355.

A

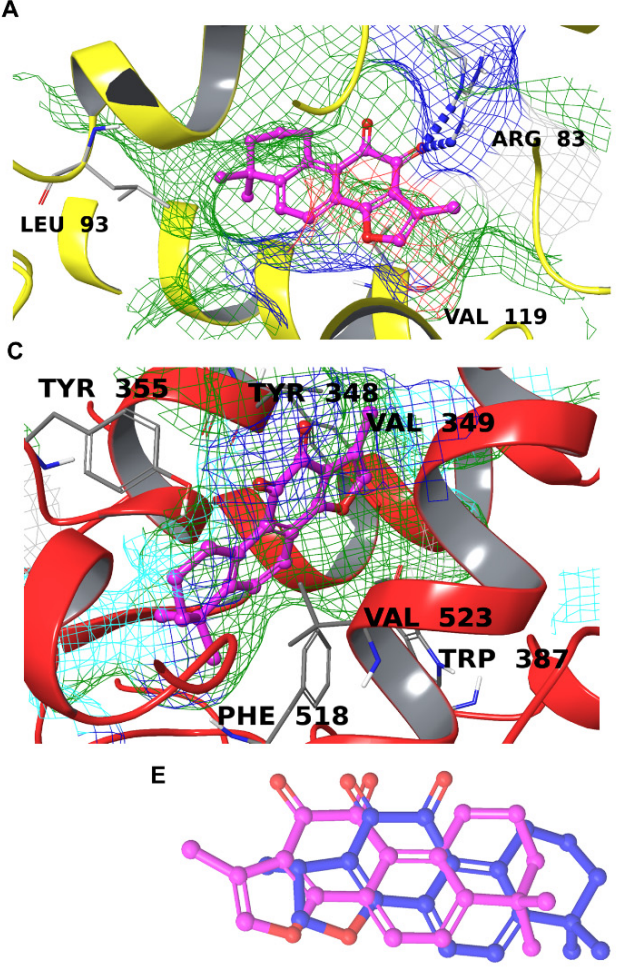

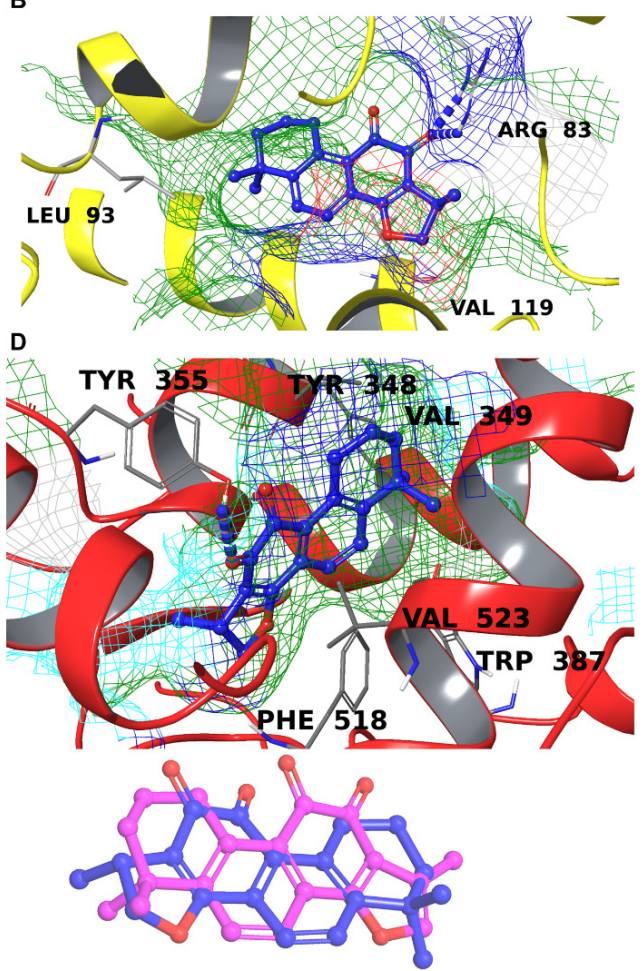

Figure 5. Binding mode of TIIA (magenta) and CRY (blue) inside the binding pockets of COX-1 (yellow ribbons) and COX-2 (red ribbons) (A-D). Hydrogen bonds are depicted as blue dotted lines. The molecular surface of the binding site is shown and colored according to residue property: green for hydrophobic residues, cyan for polar ones, blue for positively charged amino acids, and red for negatively charged ones. The important residues of the binding site are labeled in black. (E) Superimposition of the binding mode TIIA and CRY inside the binding pocket of COX-1 (right) and COX-2 (left). 


\subsubsection{5-LO}

The activity of 5-LO can be inhibited by four different types of molecules: redox, nonredox, competitive, and iron-chelating compounds [99-101]. The competitive inhibitors, in particular, may interact with the arachidonic acid binding pocket or with a putative allosteric site [101]. Considering the chemical nature of TIIA and CRY, it can be hypothesized that these may act as "canonical" competitive inhibitors (i.e., that interfere with the arachidonic acid binding site). The highly flexible arachidonic acid binding site is delimited by Phe177, Tyr181, Gln363, His367, Leu368, His372, Ile406, Ala410, Leu414, Leu420, Phe421, Asn425, Pro529, His600, Ala603, Ala606, and Leu607 [102]. Due to the structural changes required to make the binding pocket accessible, these residues were kept as "flexible" in the Induced Fit molecular docking experiments and were used to evaluate the binding of the secondary metabolites to the target protein.

Like for COX-2, TIIA was arranged differently with respect to CRY in the 5-LO binding pocket, with the carbonyl moiety facing a hydrophobic surface (Figure 6A,B). Though one of the carbonyl oxygens formed a hydrogen bond with Asn425, an important residue for inhibitor binding [102], this is not sufficient to match the optimal binding mode of CRY, probably due to the higher flexibility of this compound that can adapt to the cavity better than TIIA. In detail, the latter molecule orientated its polar moiety towards the hydrophilic part of the binding site, forming a hydrogen bond with Gln363. Moreover, two additional $\pi-\pi$ stacking interactions were made with Tyr181 and Phe421, both key residues of the 5-LO binding site. As none of the ligands showed an interaction with the iron, it can be assumed that TIIA and, more importantly, CRY represent "canonical" competitive inhibitors of 5-LO.

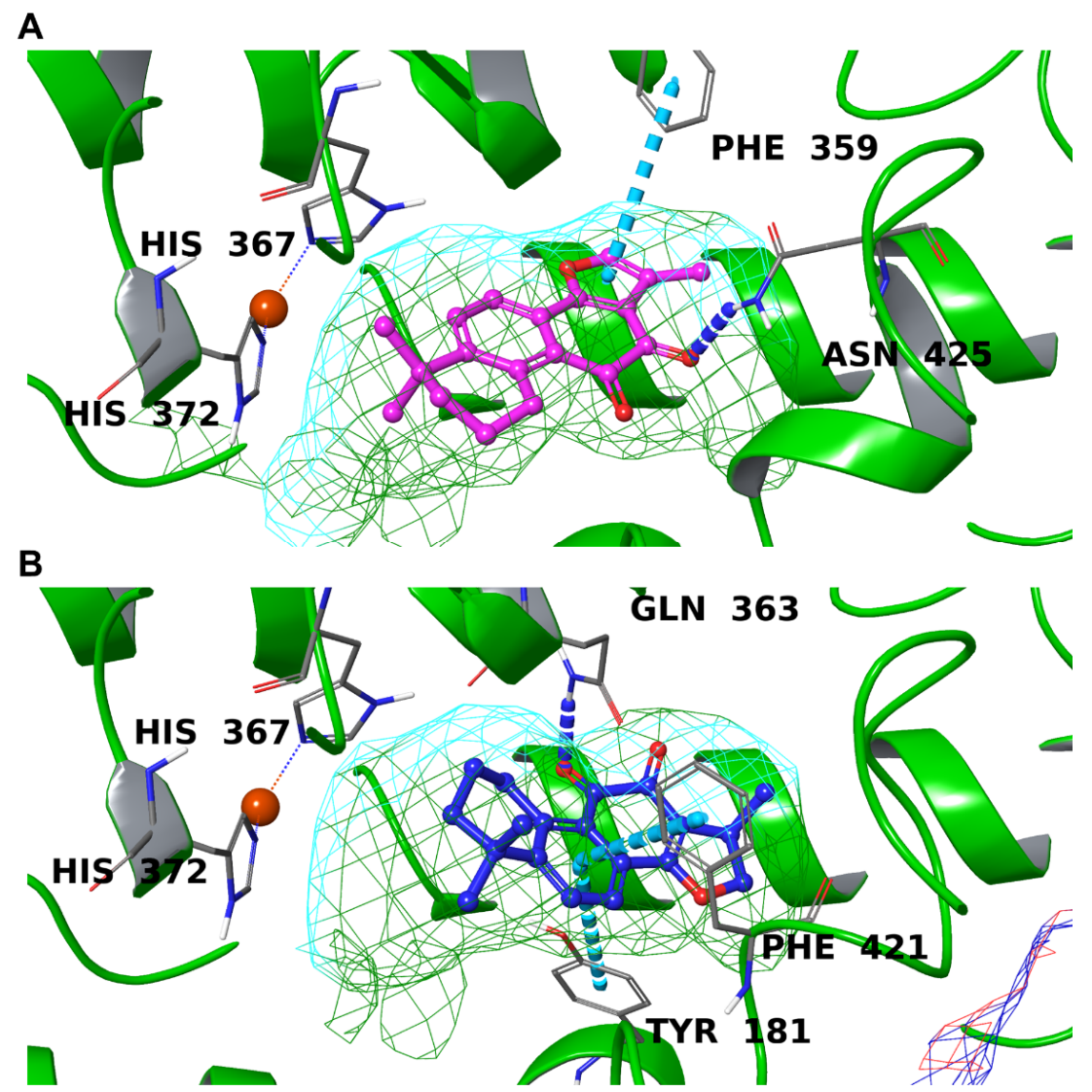

Figure 6. Binding mode of TIIA (A) and CRY (B) inside the binding pockets of 5-LO. Hydrogen bonds are depicted as blue dotted lines, and $\pi-\pi$ stackings are represented by cyan dotted lines. The molecular surface of the binding site is shown in mesh mode and colored according to residue property: green for hydrophobic residues and cyan for polar ones. The important residues of the binding site are labeled in black, and the iron is represented by an orange sphere. 


\subsection{4. mPGES-1}

mPGES-1 is a homotrimer that, therefore, contains three distinct binding sites located at the interface between two chains and contains a GSH molecule as a co-substrate in each cavity. As reported $[19,65,90,91,103]$, the binding site is delimited by Arg70, Arg110, Arg126, Ser127, Tyr130, Thr131, and Gln134 on chain A and Tyr28, Ile32, Arg38, Phe44, Asp49, and His53 on chain B. The cavity is small, and it is partially occupied by the GSH molecule, which interacts with a head group of the substrate $\mathrm{PGH}_{2}$, causing the lipophilic tails to accommodate outside the binding site [19]. From the visual inspection of the binding poses, the two compounds established interesting interactions with Tyr $130_{\text {chainA }}$ and $G \ln 134_{\text {chainA, }}$, preventing access to GSH (Figure 7A,B), and were arranged like the co-crystallized inhibitor (Figure 7C). Interestingly, CRY, due to its chemical structure, is able to orientate its methyl moiety towards a hydrophobic cavity formed on chain B (pink ribbons in Figure 7A,B), improving the overall quality of the binding with the counterpart.
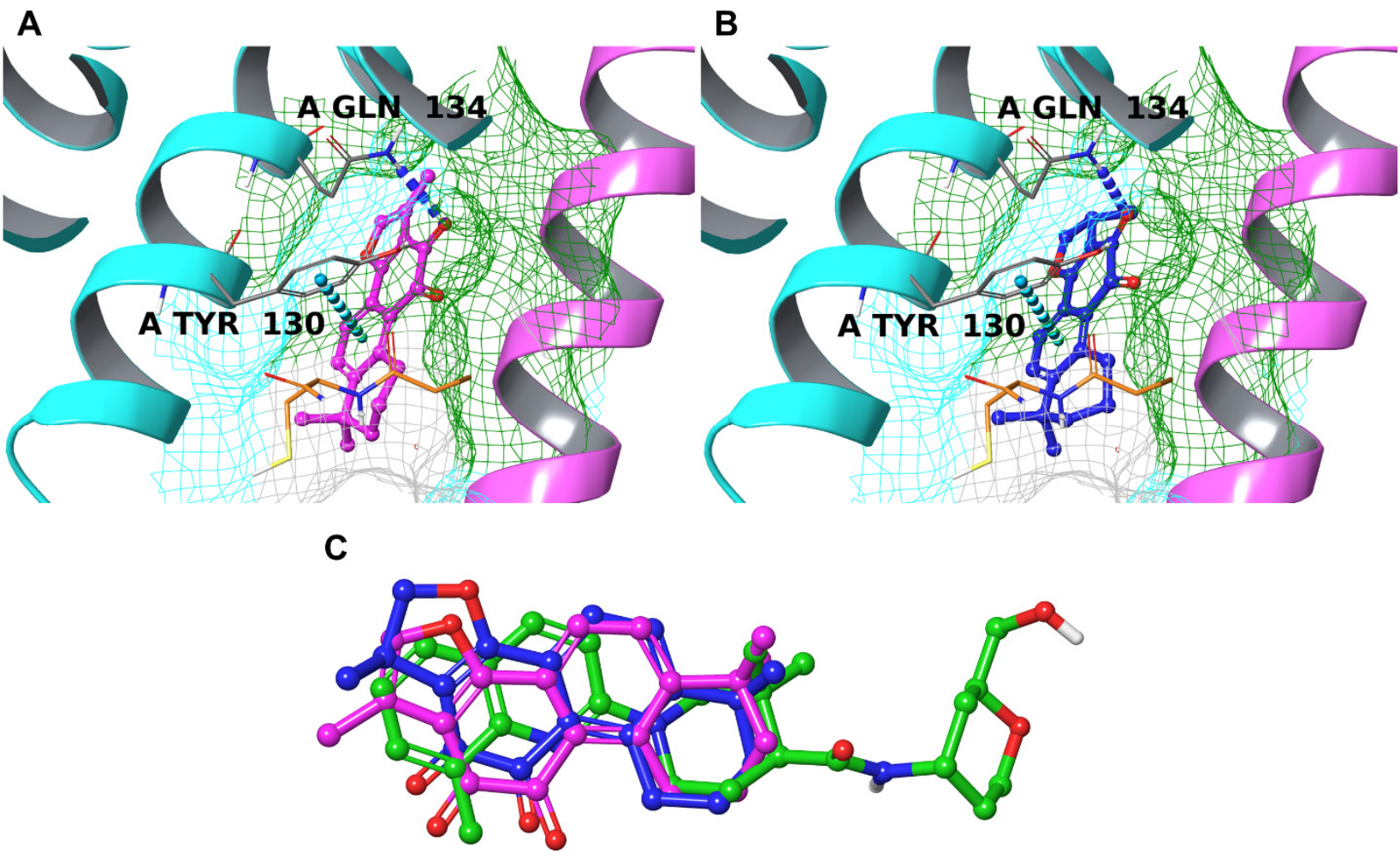

Figure 7. Binding mode of TIIA (A) and CRY (B) inside the binding pockets of mPGES-1 (cyan ribbons for chain A and pink ribbons for chain B). Hydrogen bonds are depicted as blue dotted lines and $\pi-\pi$ stackings are represented by cyan dotted lines. The molecular surface of the binding site is shown in mesh mode and colored according to residue property: green for hydrophobic residues and cyan for polar ones. The interacting residues are labeled in black, and the glutathione molecule is represented by thin tubes (orange carbons). Superposition of TIIA (pink carbons), CRY (blue carbons), and the co-crystallized ligand of mPGES-1 (green carbons) (C).

\subsubsection{PAFR}

The PAFR is a G-protein-coupled receptor that is expressed on several cell types of membranes and is activated by the platelet-activating factor (PAF) [104]. Like the other members of its family, the PAFR contains 7 transmembrane helices with the binding site located in the extracellular N-terminal domain. The major interactions are hydrophobic due to the lipophilic nature of the cavity; in particular, important amino acids are Tyr22, Trp73, Tyr77, Phe97, Trp255, His275, and Leu279 (Table 1) [47]. The spatial arrangement shown by the two compounds was very similar (Figure 8C), with an almost complete overlap between TIIA and CRY. As expected, there is a unique non-hydrophobic ( $\pi-\pi$ stacking) interaction 
with Phe152, while the rest of the energetic contribution was represented by lipophilic contacts with the extended non-polar surface (Figure 8A,B). The predicted binding energies were slightly better than the one calculated for the co-crystallized ligand, despite the latter making a higher number of interactions with the target because it is bigger and with more "interacting points" with respect to the small natural compounds. Overall, considering either the predicted binding energy and the mode of interaction, both TIIA and CRY seemed to be promising ligands for this protein.
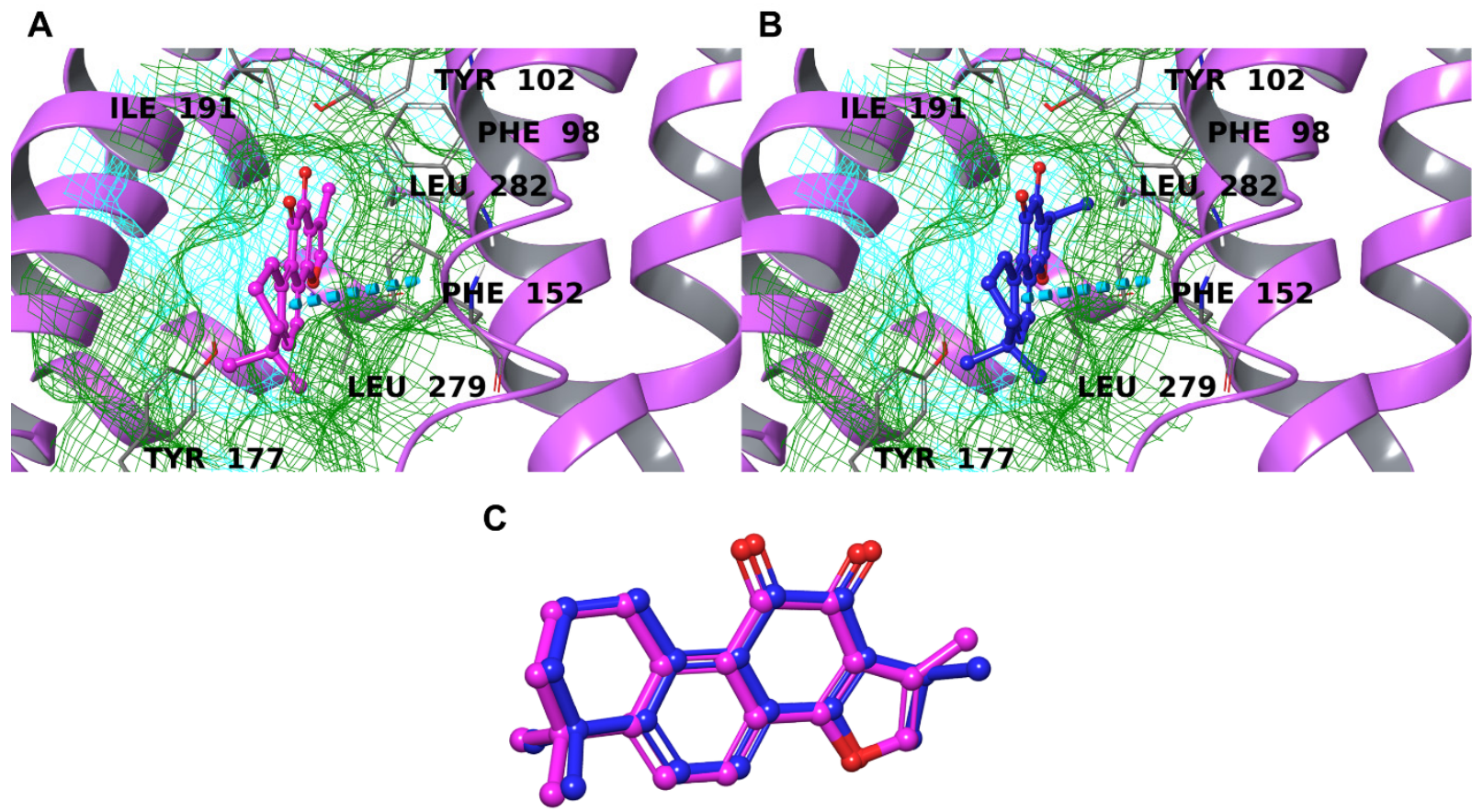

Figure 8. Binding mode of TIIA (A) and CRY (B) inside the binding pocket of PAFR (lilac ribbons). The $\pi-\pi$ stackings are represented by cyan dotted lines. The molecular surface of the binding site is shown in mesh mode and colored according to residue property: green for hydrophobic residues and cyan for polar ones. The important residues of the binding pocket are labeled in black. (C) Superimposition of TIIA (magenta) and CRY (blue).

\subsubsection{EP3 and EP4}

These two G-protein-coupled receptors interact with $\mathrm{PGE}_{2}$ and modulate some biological activities according to the tissue they are expressed in. In detail, EP3 is involved in fever generation, angiogenesis, smooth muscle contraction, and, obviously, thrombosis [48]; EP4, on the other hand, is also expressed on lymphocytes and seems to trigger the conversion of Th1 into Th17 cells [49,105].

The EP3 binding site contains three important residues (Thr206, Arg333, and Tyr114), which stabilize the carboxyl group of $\mathrm{PGE}_{2}$; the alkyl chains, instead, are accommodated on the hydrophobic surface of the cavity, reaching the receptor surface, and interact with Met137, Phe209, and Val332. Additional interactions are made with Met58 and Asp99. In this case, only CRY showed a satisfying binding mode, forming a hydrogen bond with Arg333 and interacting in a non-polar manner with Met138, Val332, and Leu329 (Figure 9). The molecule accommodated well in the pocket, directing the oxygens toward the positively charged surface and the remaining lipophilic moiety towards the hydrophobic surface. 


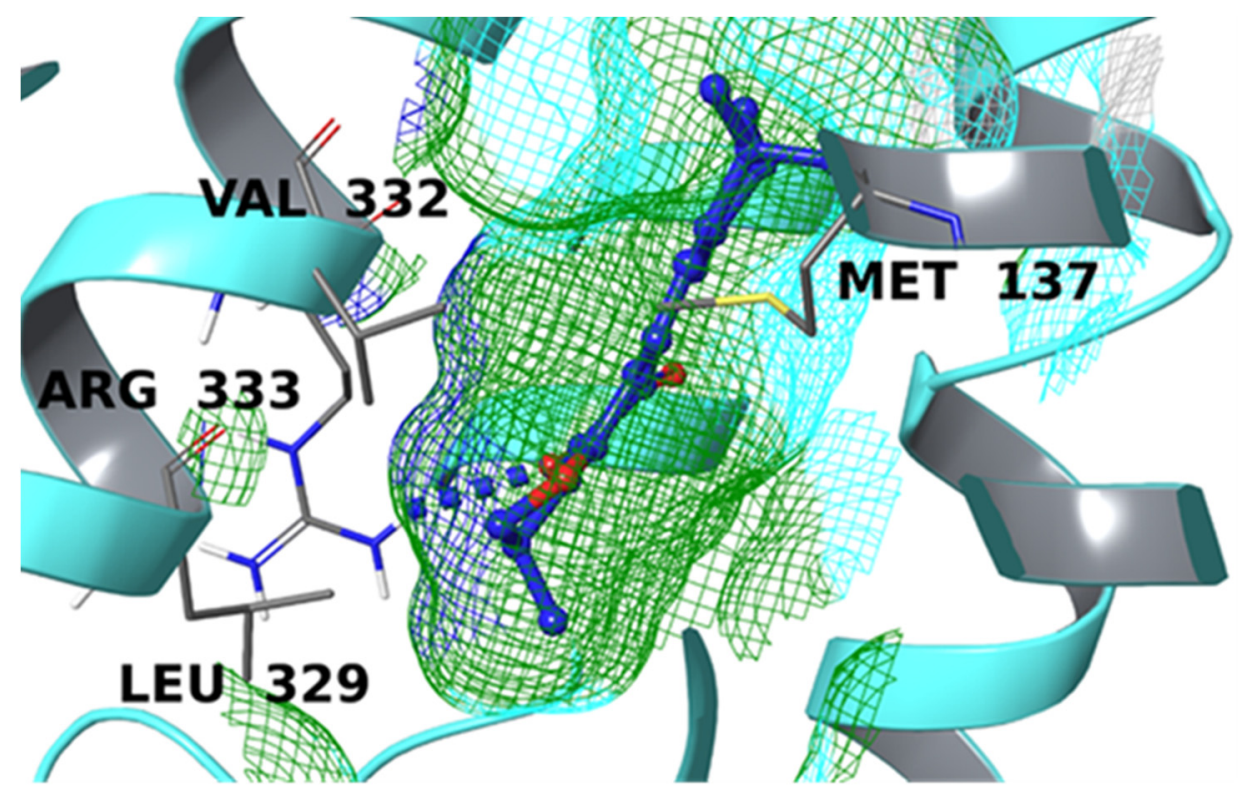

Figure 9. Binding mode CRY inside the binding pocket of EP3 (cyan ribbons). The hydrogen bond is represented by blue dotted lines. The molecular surface of the binding site is shown in mesh mode and colored according to residue property: green for hydrophobic residues, blue for positively charged amino acids, and cyan for polar ones. The important residues of the binding pocket are labeled in black.

The EP4 binding cavity is very similar to that of EP3 for both its extended hydrophobic surface and the significant role played by Arg316, which coordinates the carboxyl moiety of $\mathrm{PGE}_{2}$ like EP3. Other significant residues are Thr168, Trp169, and Leu312, highly conserved in the GPCR family, and Val72, Leu99, Ile315, Ser319, and Val320, which are specific for EP4 [49]. TIIA interacted successfully with the counterpart, making a double hydrogen bond with Arg316 and a $\pi-\pi$ interaction with Tyr80; the three-dimensional disposition was also favorable, with the carbonyl oxygens pointing at the positively charged surface and the rest of the molecule accommodated on the hydrophobic part of the cavity. Conversely, CRY was not well-accommodated in this receptor, with multiple hydrogen bonds with Arg316 as the only relevant interaction; moreover, the molecule was located far from the optimal position, almost outside the binding pocket (Figure 10).

\subsubsection{MMP-1 and MMP-2}

From the data reported in Figure 3, it was clear that neither TIIA nor CRY showed an adequate binding to MMP-1 due to the high polarity of the binding surface, which prevented a good accommodation of these lipophilic compounds inside the cavity (data not shown). Concerning MMP-2, the data were slightly better, though not satisfactory. Both molecules made two hydrogen bonds with Leu83 and Ala84, through one of the carbonyl oxygens, and a $\pi-\pi$ stacking with Tyr142 and His130, respectively, for TIIA and CRY (Figure 11). Despite the interactions with relevant amino acids, the spatial arrangement these two compounds showed was not optimal: the considerable polarity of the pocket prevented the good insertion of TIIA and CRY, leaving them in the shallow part of the binding site. 


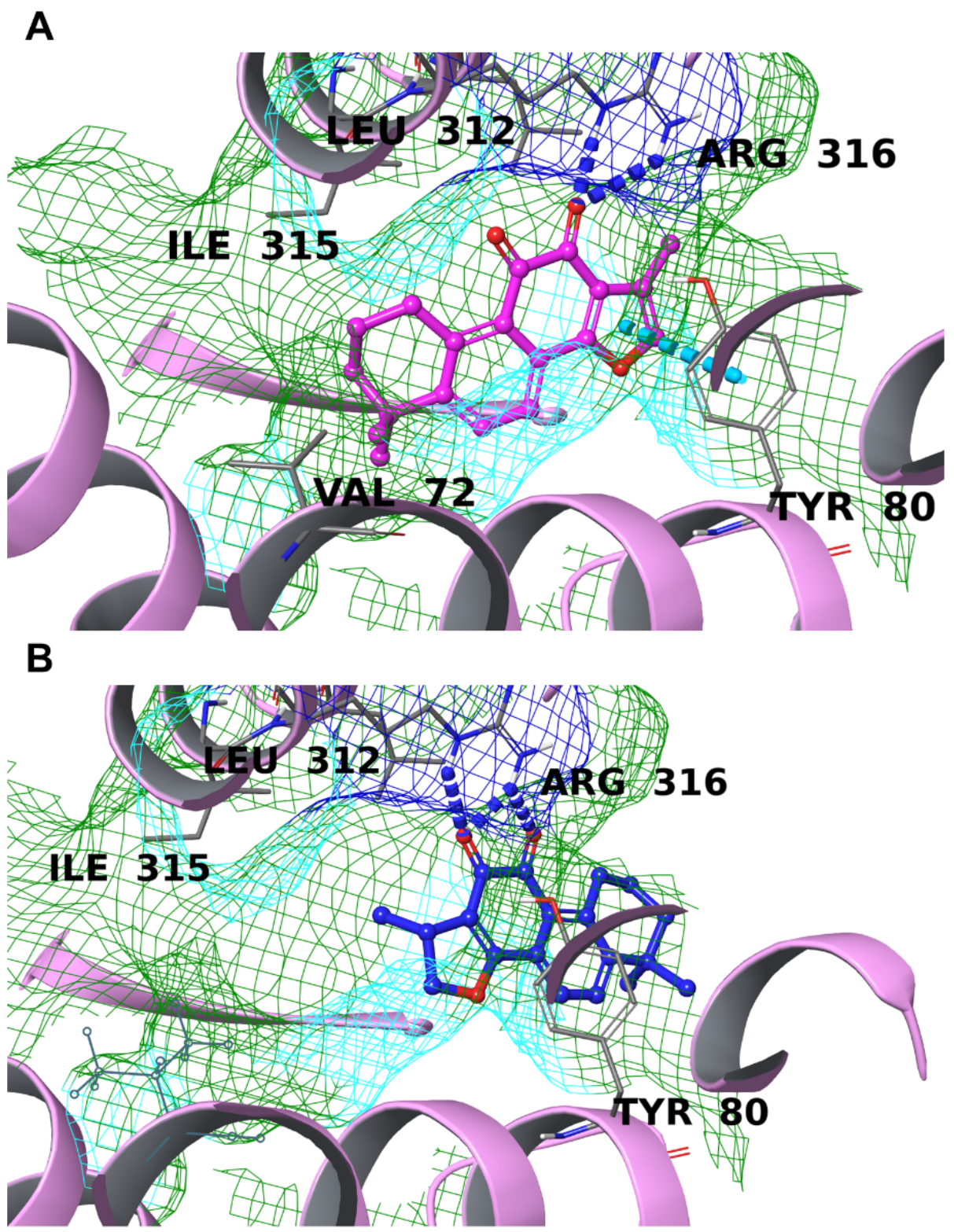

Figure 10. Binding mode TIIA (A) and CRY (B) inside the binding pocket of EP4 (light pink ribbons). The hydrogen bonds are represented by blue dotted lines, and the $\pi-\pi$ stacking is represented by a cyan dotted line. The molecular surface of the binding site is shown in mesh mode and colored according to residue property: green for hydrophobic residues, blue for positively charged residues, and cyan for polar ones. The important residues of the binding pocket are labeled in black. 


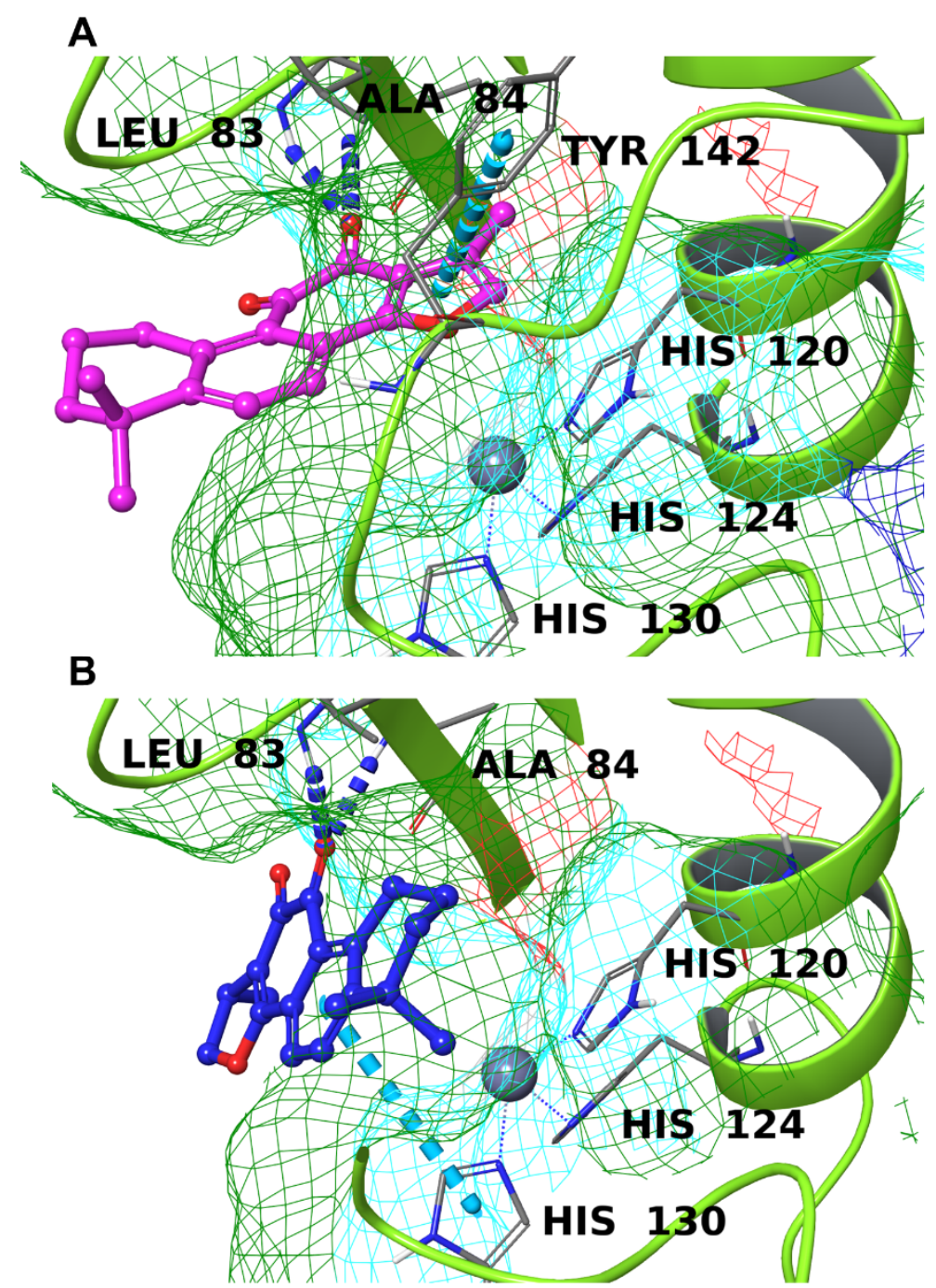

Figure 11. Binding mode TIIA (A) and CRY (B) inside the binding pocket of MMP-2 (lime green ribbons). The hydrogen bonds are represented by blue dotted lines, and the $\pi-\pi$ stackings are represented by cyan dotted lines. The molecular surface of the binding site is shown in mesh mode and colored according to residue property: green for hydrophobic residues, blue for positively charged residues, and cyan for polar ones. The important residues of the binding pocket are labeled in black, and the zinc atom is depicted as a gray sphere.

\subsubsection{Summing Up}

From the in-silico data obtained with the molecular docking experiments, both TIIA and CRY showed a discrete interaction with the considered target. In detail, COX-2, 5-LO, PAFR, and mPGES-1 appeared as the most likely protein counterpart for these natural compounds, considering the binding mode and the number of interactions with key binding site residues. For this reason, they were selected for further in vitro and in vivo studies.

\subsection{In Vitro Experiments}

Effect of TIIA and CRY on mPGES-1, 5-LO, COX-1, and COX-2 in Cell-Free Assays

The cell-free assay was used to assess the inhibition of mPGES-1 by TIIA and CRY. To do so, the human mPGES-1 in the microsomal fraction of IL- $1 \beta$-stimulated A549 cells was assayed. The two compounds were added at a concentration of $10 \mu \mathrm{M}$ to the microsomal fraction, and $20 \mu \mathrm{M} \mathrm{PGH}$ as substrate was added to determine the inhibitory activity of the enzyme. From the data collected, it emerged that CRY had a discrete inhibitory activity against mPGES-1 with an $\mathrm{IC}_{50}=1.9 \pm 0.4 \mu \mathrm{M}$, while TIIA showed no relevant interference 
with the target. These data are consistent with the predicted binding affinity of CRY to mPGES-1 and a number of interactions higher than the counterpart TIIA.

Cell-free assays using isolated enzymes were employed to assess the inhibition of 5-LO, COX-1, and COX-2 by TIIA and CRY. Thus, the isolated enzymes were incubated with TIIA or CRY $(0.3$ to $30 \mu \mathrm{M})$, and product formation was assessed by HPLC-UV. Compared to vehicle-treated controls, CRY exhibited a discrete inhibitory activity against 5-LO with an $\mathrm{IC}_{50}$ of $7.1 \mu \mathrm{M}$ (Figure 12). CRY also inhibited COX-1 and COX-2 activity, albeit to a minor degree $\left(\mathrm{IC}_{50}>30 \mu \mathrm{M}\right)$ compared to observations with 5-LO. As shown in Table 2, the overall inhibition of the tested enzymes was from 1.3 to 2.6-fold higher for CRY than for TIIA. These data support the predicted higher affinity of CRY compared to its counterpart TIIA.

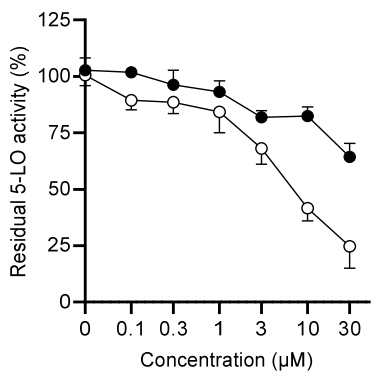

B

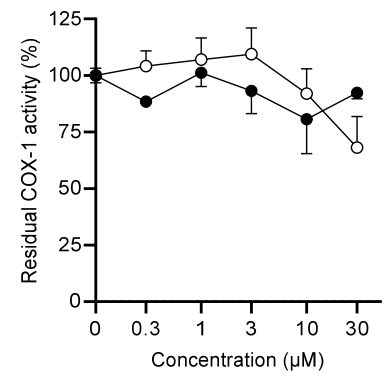

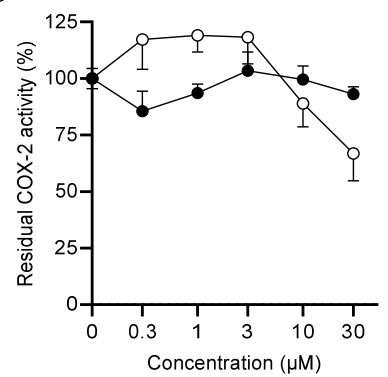

Figure 12. Effect of TIIA and CRY on the activity of 5-LO (A), COX-1 (B), and COX-2 (C). Data are presented as means \pm SEM of residual enzyme activity after incubation of isolated 5-LO $(n=7)$, COX-1 $(n=3)$, and COX-2 $(n=4)$ with TIIA or CRY at the indicated concentrations. Statistical analysis was conducted by non-constrained non-linear regression of inhibitor vs. response (variable slope).

Table 2. Residual activity of 5-LO, COX-1, and COX-2 after incubation with TIIA or CRY at $30 \mu \mathrm{M}$.

\begin{tabular}{cccc}
\hline \multirow{2}{*}{ Compound } & \multicolumn{2}{c}{ Residual Activity (\% of Vehicle-Treated Enzymes) } \\
\cline { 2 - 4 } & $\mathbf{5 - L O}$ & COX-1 & COX-2 \\
\hline TIIA & 64.3 & 92.4 & 93.1 \\
CRY & 24.7 & 68.2 & 66.8 \\
\hline
\end{tabular}

\subsection{Effect of TIIA and CRY on EP Receptor}

Since $\mathrm{PGE}_{2}$ has been reported to exhibit a biphasic effect on platelet aggregation via EP receptors, we sought to examine on clot homogenates, the effect of TIIA and CRY on EP2, EP3, and EP4 by western blot analysis. Representative results presented in Figure 13A show that both diterpenoids did not alter the expression of EP2 (Figure 13B) and EP4 (Figure 13C). Interestingly, a significant reduction of EP3 expression in CRY (but not TIIA)-treated mice compared to the vehicle group ( $p \leq 0.01$ ) was found (Figure 13D). Densitometric values are expressed as an OD ratio against tubulin. The uncropped and triplicate of the original Western blots are presented in Supplementary Figures S1-S4.

\subsection{Effect of TIIA and CRY on Clot Retraction and Bleeding Time}

The effect of TIIA and CRY was investigated on platelet activation by performing an ex vivo model of clot retraction. Results from this in vivo model were assessed macroscopically by the evaluation of clot morphology (Figure 14A-E) and numerically (clot score) by clot weights and residual serum volumes. It was observed that samples from TIIA- and CRYtreated mice (10 mg/kg; i.p.) were much less retracted (TIIA: $0.068 \pm 0.009 \mathrm{~g}, p \leq 0.05$; CRY: $0.048 \pm 0.011 \mathrm{~g}, p \leq 0.01)$ compared to the vehicle group $(0.096 \pm 0.009 \mathrm{~g})$, suggesting that both diterpenoids significantly decreased the clot retraction rates of platelets. A similar effect was found for ASA-treated mice $(0.042 \pm 0.008 \mathrm{~g}$ vs. $0.099 \pm 0.012 \mathrm{~g}, p \leq 0.01)$ (Figure 14F). Congruently, as shown in Figure 14G, the CRY-treated group resulted in a more prominent production of serum compared to the vehicle group $(171.0 \pm 7.35 \mu \mathrm{L}$ 
vs. $139 \pm 12.08 \mu \mathrm{L}, p \leq 0.05)$. Successively, in order to support the hypothesis that both diterpenoids could affect hemostasis and thrombus formation, in vivo tail bleeding assay was performed [106]. As shown in Figure 14H, pretreatment with TIIA and CRY significantly increased the bleeding time in mice (TIIA: $2.07 \pm 0.17 \mathrm{~min}, p \leq 0.01$; CRY: $2.44 \pm 0.12 \mathrm{~min}, p \leq 0.001)$ compared to the vehicle group $(1.33 \pm 0.14 \mathrm{~min})$. Similar results were observed after ASA administration (2.07 $\pm 0.22 \mathrm{~min}$ vs. $1.04 \pm 0.19 \mathrm{~min}, p \leq 0.01)$.
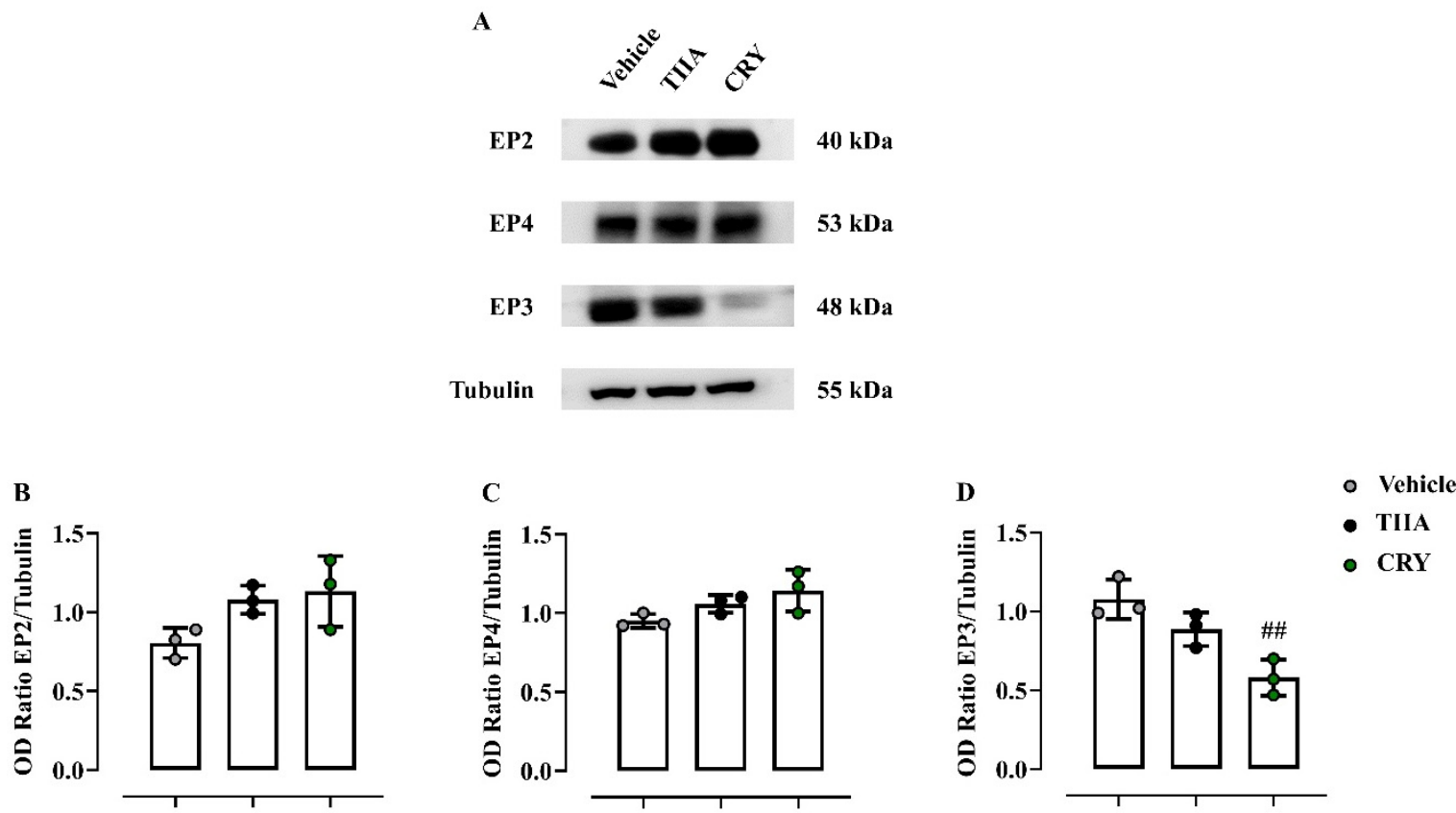

Figure 13. Effect of TIIA and CRY on EPs receptor. Representative western blotting (A) and related cumulative densitometric analyses of EP2 (B), EP4 (C), EP3 (D) of clot homogenates from mice injected i.p. with TIIA $(10 \mathrm{mg} / \mathrm{kg})$ or CRY $(10 \mathrm{mg} / \mathrm{kg}) 1 \mathrm{~h}$ before the experiments. Data are presented as means $\pm \mathrm{SD}$ of three separate independent experiments run each with $n=7$ mice per group pooled. Statistical analysis was conducted by using one-way ANOVA followed by Bonferroni's for multiple comparisons. ${ }^{\# \#} p<0.01$ vs. vehicle group.

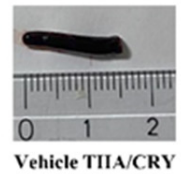

B

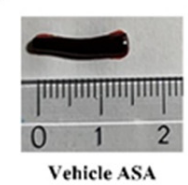

C

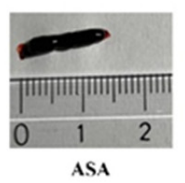

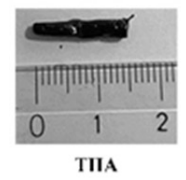

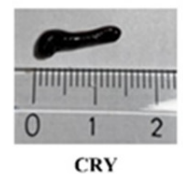

- Vehicle TIIA/CRY O Vehicle ASA

- ASA

- TIIA

OCRY
F

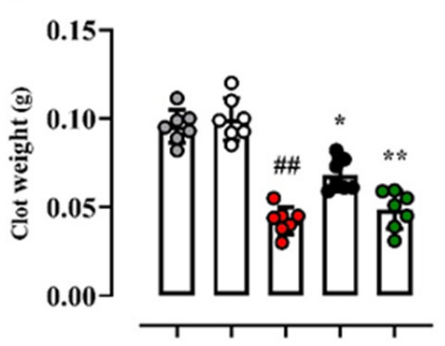

G

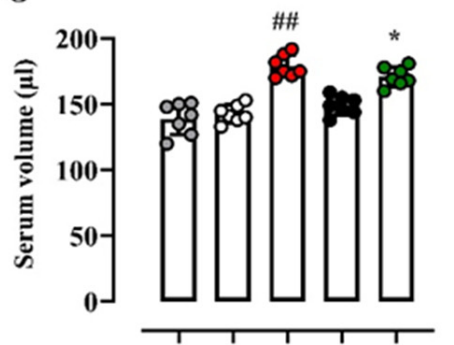

H

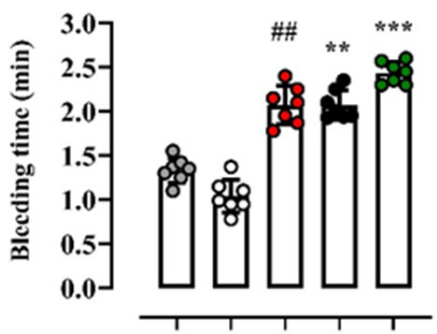

Figure 14. Effect of TIIA and CRY on in vivo clot retraction and bleeding time. Not-anticoagulated blood samples were incubated into Microvette ${ }^{\circledR} 300 \mathrm{Z}$, containing clotting activator, at room temperature 
for $2 \mathrm{~h}$. The impact of TIIA and CRY on platelet activation was evaluated by clot morphology (A-E), quantification of clot weights $(\mathbf{F})$, and residual serum volumes $(\mathbf{G})$. The effect on platelet hemostatic function and thrombotic activity was also determined by tail bleeding time $(\mathbf{H})$. TIIA $(10 \mathrm{mg} / \mathrm{kg})$, CRY $(10 \mathrm{mg} / \mathrm{kg})$, or ASA $(10 \mathrm{mg} / \mathrm{kg}$ ) were administered i.p. to CD-1 mice $1 \mathrm{~h}$ before the experiments. Data are presented as means $\pm \mathrm{SD}$ of $n=7$ mice per group. Statistical analysis was conducted by one-way ANOVA followed by Bonferroni's for multiple comparisons. ${ }^{\# \#} p \leq 0.01$ vs. vehicle ASA; ${ }^{*} p \leq 0.05,{ }^{* *} p \leq 0.01,{ }^{* * *} p \leq 0.001$ vs. vehicle TIIA/CRY.

\section{Discussion}

Inflammation and hemostasis cannot be considered as two separate processes since there are several connecting points making them part of a unique, defensive host response. There is much evidence that inflammation triggers hemostatic imbalance. Experimental and clinical data demonstrate that inflammation is associated with an increased risk of cardiovascular events [107-109]. An important aspect to be considered when the link between hemostasis and inflammation is examined is the contribution of platelets to both processes $[110,111]$. Platelets are considered effective elements of the inflammatory system. Under physiological conditions, platelets circulate freely in the blood. On the contrary, when the endothelium is damaged, platelets adhere to collagen fibers of the sub-endothelium, thereby becoming activated. Activated platelets express molecules on their surface driving platelet endothelium adhesion and platelet-leukocytes interaction. In this work, a combined in silico, in vitro, in vivo, and ex-vivo approach was performed to prove a possible use of tanshinones (TIIA and CRY) in the prevention of thrombotic events. Our attention was focused on ten key targets of the inflammatory/pro-thrombotic cascade: sPLA 2 , COX-1, COX-2, 5-LO, mPGES-1, EP3, and EP4 receptors, PAFR, MMP-1, and MMP-2.

From the analysis of the docking poses, it was clear that both compounds are able to interact significantly with COX-2, 5-LO, PAFR, and mPGES-1, which are key proteins involved not only in the onset of inflammation but also with a cardiovascular alteration of platelet activity (and hyper-reactivity) and, to a lesser extent, thrombotic and thromboembolic disease [112,113]. Moreover, a difference in the binding to the two isoforms of COX was highlighted, suggesting a preferential binding of CRY to COX-2. This compound seemed to adapt better to the binding pocket of several of the considered enzymes due to its less rigid chemical structure. This may suggest that CRY acts as a multitarget rather than a selective inhibitor. Consistently, results from cell-free COX-1 and COX-2 activity assays revealed the similar moderate inhibition of the two COX isoforms by CRY, while TIIA was essentially inactive up to $30 \mu \mathrm{M}$ (highest concentration tested). In addition, in 5-LO activity assays using the isolated human recombinant enzyme, CRY displayed more efficient inhibition than TIIA. These data confirmed the hypothesis that CRY is capable of a multitarget inhibitory effect, and its mechanism of action should not be strictly compared to known selective inhibitors (like rofecoxib for COX-2). This broad spectrum of action could represent a significant advantage as it allows for the interference with more than one key player in the thrombotic events, generating a synergism that exerts the biological effect of a low therapeutic dose.

Interestingly, concerning EP3 and EP4, two of the prostaglandin receptors, specular results emerged, with CRY showing a better binding on EP3 and TIIA on EP4. It is important to notice that only with PAFR did the two compounds show an interaction with the target better than the co-crystallized molecule, putting it in a pivotal role as the focus for future work.

Owing to the undesirable effects of COX-2-selective inhibitors (thrombotic events, hypertension, and heart failure), interest was focused on mPGES-1 as an alternative target for the development of analgesics and anti-inflammatory drugs [12]. The thought was that the analgesic efficacy would be largely, if not totally, conserved by PGE 2 suppression, while most of the cardiovascular risk would be minimized by conserving or even boosting the cardioprotective $\mathrm{PGI}_{2}$ production [114]. Indeed, global or myeloid-specific deletion of 
mPGES-1 has proven efficacy in restraining atherogenesis, attenuating the proliferative response to vascular injury, and limiting aortic aneurysm formation [115-119].

To further support this evidence, an in vivo and ex vivo model of platelet aggregation and blood stasis, namely mouse clot retraction and bleeding time, was also performed. Platelet adhesion to the extracellular matrix in flowing blood is the first and crucial step for thrombus formation. During the platelet adhesion, pseudopodia are formed, which supports an effective attachment to the injured surface of the blood vessel wall [120]. Clot retraction, the shrinking of a blood clot that involves platelet adhesion and aggregation, is a process driven by extracellular signaling that results in the contraction of the fibrin mesh. The ability of platelets to drive clot retraction is a surrogate measure of outside-in signaling [73]. Our results showed that both diterpenoids, and in particular CRY, were able to increase the bleeding time in mice with an effect similar to those observed after ASA administration. Interestingly, results from ex vivo experiments displayed a promising anti-coagulant property of CRY with a profile greater than ASA.

$\mathrm{PGE}_{2}$ acts on four specific GPCR subtypes, termed EP1-4. The activation of these receptors by $\mathrm{PGE}_{2}$ or artificial compounds stimulates distinct signal transduction pathways and mediates various biological functions [28]. The EP1 receptor couples to Gq-proteins to increase intracellular $\mathrm{Ca}^{2+}$ concentration. The EP2 and EP4 receptors couple to Gsproteins and evoke an increase in intracellular cAMP concentration. EP3 receptor mainly couples to Gi-proteins to decrease cAMP production, while it has at least eight variants that may activate other different signaling pathways, for example, elevate intracellular $\mathrm{Ca}^{2+}$ or activate the small G-protein Rho. The involvement of the four $\mathrm{PGE}_{2}$ receptors in cardiovascular function has been studied with various genetic deletion approaches or small molecule agonists or antagonists, and the conclusions varied [10]. Thrombosis is the most pronounced risk signal associated with COX-2 selective NSAIDs [121]. The inhibition of COX-2 or the deletion of IP (PGI 2 receptor) significantly accelerated thrombogenesis, reflected by the shortened time to vascular occlusion after photochemical injury of the carotid artery and reduced thrombogenesis after laser-induced cremaster arterioles injury; however, these effects were not observed in either global or myeloid cell mPGES-1 knockout mice $[115,118]$. Effects on both augmented $\mathrm{PGI}_{2}$ and suppressed $\mathrm{PGE}_{2}$ might be relevant to this beneficial phenotype: $\mathrm{PGI}_{2}$ restrains thrombogenesis, while $\mathrm{PGE}_{2}$ elicits platelet aggregation at low concentrations via EP3 [29]. PGE 2 has been reported to exhibit a biphasic effect on platelet aggregation. While EP1 expression is lacking, the other three $\mathrm{PGE}_{2}$ receptors, EP2, EP3, and EP4, are all expressed in platelets, and the expression level of EP3 is much higher than EP2 and EP4. In detail, EP3 mediates the pro-aggregatory effect of $\mathrm{PGE}_{2}$. EP3 agonists had shown concentration-dependent potentiation of platelet aggregation in vitro [29]. In vivo, EP3 gene depletion mice showed significantly prolonged tail bleeding time and when challenged with arachidonic acid, lung thrombus formation, and mortality [30]. In addition, by mechanical rupture of the plaque with scratching in a murine model, the atherothrombosis was drastically decreased when there was a lack of EP3 in platelets [122]. Indeed, DG-041, a direct-acting EP3 antagonist, has been considered as an effective antiplatelet and anti-atherothrombosis drug without increasing the bleeding risk [31,123]. In contrast, the EP2 and EP4 signaling mediate the anti-aggregatory effects of $\mathrm{PGE}_{2}$, albeit the IP plays the predominant inhibitory role at higher $\mathrm{PGE}_{2}$ concentrations. Notably, these inhibitory effects of EP2 and EP4 might only be efficient when the EP3 receptor is absent [124]. Nevertheless, $\mathrm{PGE}_{2}$ sensitizes platelets to their agonists, such as thrombin or collagen through the activation of its EP3 receptor, while $\mathrm{PGE}_{2}$ inhibits platelet activity through EP2 and EP4 receptors [124]. Notably, our results shown that CRY, but not TIIA, was able to reduce the expression of EP3 isoform on mice clots without interfering with EP2 and EP4 enzymatic activity. This is of extreme importance from the perspective of a selective blockade of the EP3 activity (and/or activation of EP2 or EP4) in view of rational strategies for developing novel antiplatelet agents and/or preventing thrombogenesis. All these findings are strengthened by the lack of toxic effects and by a low cytotoxic profile for tanshinones in both human and murine cell lines [125-127]. Moreover, recent reports have 
revealed that both TIIA and CRY are able to selectively induce apoptosis in different cancer cell lines in a concentration and time-dependent manner [128-130].

\section{Conclusions}

In conclusion, this study aimed to use a translational approach to investigate and rationalize the anti-aggregating properties of two secondary metabolites of S. miltiorrhiza Bunge. First, molecular docking experiments were carried out on key targets of the inflammatory/thrombogenic pathway to highlight putative partners. The binding poses were evaluated in terms of energy and interactions with the key residues of the protein counterparts. From the analysis of the corresponding results, COX-2, 5-LO, PAFR, and mPGES-1 emerged as the most probable interacting macromolecules for the two compounds. After the rationalization at the molecular level of the ligand-protein complexes, with in vitro, in vivo, and ex-vivo studies, the predicted binding was confirmed, highlighting a preferential multitarget action of CRY. The results showed, for the first time, that TIIA, and in particular CRY, are able to interact significantly with the key proteins involved not only in the onset of inflammation but also in platelet activity (and hyper-reactivity). Future preclinical and clinical investigations, together with this evidence, could provide the scientific basis to consider these compounds as an alternative therapeutic approach for thrombotic- and thromboembolic-based diseases.

Supplementary Materials: The following supporting information can be downloaded at: https:/ / www.mdpi.com/article/10.3390/biom12010099/s1. Original blot images (Figures S1-S4), redocking binding poses with corresponding RMSD values (Figure S5), and Ballesteros-Weinstein numbering scheme of PAFR, EP3, and EP4.

Author Contributions: Investigation, A.S., S.D.V., M.G.C., G.L., F.R., K.F., R.K.H., G.M.C., N.M. and F.M.; writing—original draft preparation, S.D.V., M.G.C., G.L. and F.M.; writing-review and editing, A.K., O.W., M.I., F.M. and G.B.; supervision, O.W., F.M. and G.B. All authors have read and agreed to the published version of the manuscript.

Funding: The research leading to these results received funding from AIRC under IG 2018-ID. 21397 project-P.I. Bifulco Giuseppe. This work was also supported by MIUR (PRIN 2017; 2017A95NCJ, "Stolen molecules-Stealing natural products from the depot and reselling them as new drug candidates"), a 2014 to 2020 POR CAMPANIA FESR grant from the Regional Council of Campania Region, entitled "Campania OncoTerapie-Combattere la resistenza tumorale: piattaforma integrata multidisciplinare per un approccio tecnologico innovativo alle oncoterapie", and by the Deutsche Forschungsgemeinschaft SFB 1278/1 PolyTarget-316213987 (to O.W.). A.S. is supported by the Dompé Farmaceutici S.p.A fellowship for the PhD program in "Nutraceuticals, functional foods and human health" (University of Naples Federico II), whereas F.R. is supported by the University of Naples Federico II PhD scholarship in Pharmaceutical Sciences.

Institutional Review Board Statement: All animal care and experimental procedures complied with the international and national law and policies and were approved (authorization number: 545/2021-PR) by the Italian Ministry of Health (EU Directive 2010/63/EU for animal experiments and the Basel declaration including the 3Rs concept).

Informed Consent Statement: Not applicable.

Data Availability Statement: Not applicable.

Conflicts of Interest: The authors declare no conflict of interest.

\section{Abbreviations}

12-HHT: 12-hydroxyheptadecatrienoic acid; 5-LO, 5-lipoxygenase; ASA, acetylsalicylic acid; COX-, cyclooxygenase-; cPGES, cytosolic prostaglandin $\mathrm{E}_{2}$ synthase; CRY, Cryptotanshinone; EGF, epidermal growth factor; EP, endothelial prostaglandin; ERKs, extracellular signal-regulated kinases; GPCR, G-protein-coupled receptors; GSH, glutathione; i.p., intraperitoneally; IL-, interleukin-; LTs, leukotrienes; MMPs, matrix metalloproteinase; mPGES-, microsomal prostaglandin E synthase-; NSAIDs, non-steroidal anti-inflammatory drugs; PAF, platelet-activating factor; PAFR, platelet-activating 
factor receptor; PBS-T, PBS-Tween 20; PGs, prostaglandins; $\mathrm{SPLA}_{2}$, secreted phospholipase $\mathrm{A}_{2} ; \mathrm{RT}$, room temperature; TIIA, Tanshinone IIA; TXA, thromboxane.

\section{References}

1. Serhan, C.N.; Brain, S.D.; Buckley, C.D.; Gilroy, D.W.; Haslett, C.; O’Neill, L.A.J.; Perretti, M.; Rossi, A.G.; Wallace, J.L. Resolution of inflammation: State of the art, definitions and terms. FASEB J. 2007, 21, 325-332. [CrossRef]

2. Serhan, C.N. Pro-resolving lipid mediators are leads for resolution physiology. Nature 2014, 510, 92-101. [CrossRef]

3. D'Acquisto, F.; Maione, F.; Pederzoli-Ribeil, M. From IL-15 to IL-33: The never-ending list of new players in inflammation. Is it time to forget the humble aspirin and move ahead? Biochem. Pharmacol. 2010, 79, 525-534. [CrossRef]

4. Sugimoto, M.A.; Sousa, L.P.; Pinho, V.; Perretti, M.; Teixeira, M.M. Resolution of inflammation: What controls its onset? Front. Immunol. 2016, 7, 160. [CrossRef] [PubMed]

5. Perretti, M.; Cooper, D.; Dalli, J.; Norling, L.V. Immune resolution mechanisms in inflammatory arthritis. Nat. Rev. Rheumatol. 2017, 13, 87-99. [CrossRef] [PubMed]

6. Libby, P. Inflammation in atherosclerosis. Nature 2002, 420, 868-874. [CrossRef]

7. Esmon, C.T. Inflammation and thrombosis. J. Thromb. Haemost. 2003, 1, 1343-1348. [CrossRef]

8. Franco, A.T.; Corken, A.; Ware, J. Platelets at the interface of thrombosis, inflammation, and cancer. Blood 2015, 126, 582-588. [CrossRef] [PubMed]

9. Funk, C.D. Prostaglandins and leukotrienes: Advances in eicosanoid biology. Science 2001, 294, 1871-1875. [CrossRef] [PubMed]

10. Ricciotti, E.; Fitzgerald, G.A. Prostaglandins and Inflammation. Atertio. Thromb. Vasc. Biol. 2011, 31, 986-1000. [CrossRef] [PubMed]

11. Hawkey, C.J. COX-2 inhibitors. Lancet 1999, 353, 307-314. [CrossRef]

12. Koeberle, A.; Werz, O. Perspective of microsomal prostaglandin E2 synthase-1 as drug target in inflammation-related disorders. Biochem. Pharmacol. 2015, 98, 1-15. [CrossRef] [PubMed]

13. Cuzzocrea, S.; Wayman, N.S.; Mazzon, E.; Dugo, L.; Di Paola, R.; Serraino, I.; Britti, D.; Chatterjee, P.K.; Caputi, A.P.; Thiemermann, $\mathrm{C}$. The cyclopentenone prostaglandin 15-deoxy- $\Delta 12,14$-prostaglandin $\mathrm{J} 2$ attenuates the development of acute and chronic inflammation. Mol. Pharmacol. 2002, 61, 997-1007. [CrossRef]

14. Samuelsson, B.; Morgenstern, R.; Jakobsson, P.-J. Membrane prostaglandin E synthase-1: A novel therapeutic target. Pharmacol. Rev. 2007, 59, 207-224. [CrossRef] [PubMed]

15. Maione, F.; Casillo, G.M.; Raucci, F.; Iqbal, A.J.; Mascolo, N. The functional link between microsomal prostaglandin E synthase-1 (mPGES-1) and peroxisome proliferator-activated receptor $\gamma$ (PPAR $\gamma)$ in the onset of inflammation. Pharmacol. Res. 2020, 157, 104807. [CrossRef]

16. Mancini, J.A.; Blood, K.; Guay, J.; Gordon, R.; Claveau, D.; Chan, C.C.; Riendeau, D. Cloning, expression, and up-regulation of inducible rat prostaglandin e synthase during lipopolysaccharide-induced pyresis and adjuvant-induced arthritis. J. Biol. Chem. 2001, 276, 4469-4475. [CrossRef] [PubMed]

17. Trebino, C.E.; Stock, J.L.; Gibbons, C.P.; Naiman, B.M.; Wachtmann, T.S.; Umland, J.P.; Pandher, K.; Lapointe, J.-M.; Saha, S.; Roach, M.L.; et al. Impaired inflammatory and pain responses in mice lacking an inducible prostaglandin E synthase. Proc. Natl. Acad. Sci. USA 2003, 100, 9044. [CrossRef]

18. Uematsu, S.; Matsumoto, M.; Takeda, K.; Akira, S. Lipopolysaccharide-dependent prostaglandin E2 production Is regulated by the glutathione-dependent prostaglandin E2 synthase gene induced by the Toll-Like Receptor 4/MyD88/NF-IL6 pathway. J. Immunol. 2002, 168, 5811-5816. [CrossRef]

19. Sjögren, T.; Nord, J.; Ek, M.; Johansson, P.; Liu, G.; Geschwindner, S. Crystal structure of microsomal prostaglandin E2 synthase provides insight into diversity in the MAPEG superfamily. Proc. Natl. Acad. Sci. USA 2013, 110, 3806. [CrossRef]

20. Raouf, J.; Mobarrez, F.; Larsson, K.; Jakobsson, P.-J.; Korotkova, M. Deletion of mPGES-1 affects platelet functions in mice. Clin. Sci. 2016, 130, 2295-2303. [CrossRef] [PubMed]

21. Tang Soon, Y.; Monslow, J.; Gregory, R.G.; Todd, L.; Pawelzik, S.-C.; Chen, L.; Lawson, J.; Puré, E.; FitzGerald Garret, A. Cardiovascular consequences of prostanoid I receptor deletion in microsomal prostaglandin E synthase-1-deficient hyperlipidemic mice. Circulation 2016, 134, 328-338. [CrossRef] [PubMed]

22. Tarantino, E.; Amadio, P.; Squellerio, I.; Porro, B.; Sandrini, L.; Turnu, L.; Cavalca, V.; Tremoli, E.; Barbieri, S.S. Role of thromboxane-dependent platelet activation in venous thrombosis: Aspirin effects in mouse model. Pharmacol. Res. 2016, emph107, 415-425. [CrossRef]

23. Gresele, P.; Falcinelli, E.; Sebastiano, M.; Momi, S. Chapter Four-Matrix Metalloproteinases and Platelet Function. In Progress in Molecular Biology and Translational Science; Khalil, R.A., Ed.; Academic Press: Cambridge, MA, USA, 2017; Volume 147, pp. 133-165.

24. Zhu, L.; Zhang, Y.; Guo, Z.; Wang, M. Cardiovascular Biology of Prostanoids and Drug Discovery. Arterioscler. Thromb. Vasc. Biol. 2020, 40, 1454-1463. [CrossRef] [PubMed]

25. Ushikubi, F.; Hirata, M.; Narumiya, S. Platelet prostaglandin receptors. In Platelets and Their Factors; von Bruchhausen, F., Walter, U., Eds.; Springer: Berlin/Heidelberg, Germany, 1997; pp. 135-154. 
26. Rivera, J.; Lozano, M.L.; Navarro-Núñez, L.; Vicente, V. Platelet receptors and signaling in the dynamics of thrombus formation. Haematologica 2009, 94, 700-711. [CrossRef]

27. Friedman, E.A.; Ogletree, M.L.; Haddad, E.V.; Boutaud, O. Understanding the role of prostaglandin E2 in regulating human platelet activity in health and disease. Thromb. Res. 2015, 136, 493-503. [CrossRef] [PubMed]

28. Breyer, R.M.; Bagdassarian, C.K.; Myers, S.A.; Breyer, M.D. Prostanoid receptors: Subtypes and signaling. Annu. Rev. Pharmacool. Toxicol. 2001, 41, 661-690. [CrossRef]

29. Fabre, J.-E.; Nguyen, M.; Athirakul, K.; Coggins, K.; McNeish, J.D.; Austin, S.; Parise, L.K.; FitzGerald, G.A.; Coffman, T.M.; Koller, B.H. Activation of the murine EP3 receptor for PGE2 inhibits cAMP production and promotes platelet aggregation. J. Clin. Invest. 2001, 107, 603-610. [CrossRef]

30. Ma, H.; Hara, A.; Xiao, C.Y.; Okada, Y.; Takahata, O.; Nakaya, K.; Sugimoto, Y.; Ichikawa, A.; Narumiya, S.; Ushikubi, F. Increased bleeding tendency and decreased susceptibility to thromboembolism in mice lacking the prostaglandin E receptor subtype EP3 Circulation 2001, 104, 1176-1180. [CrossRef]

31. Tilly, P.; Charles, A.-L.; Ludwig, S.; Slimani, F.; Gross, S.; Meilhac, O.; Geny, B.; Stefansson, K.; Gurney, M.E.; Fabre, J.-E. Blocking the EP3 receptor for PGE2 with DG-041 decreases thrombosis without impairing haemostatic competence. Cardiovasc. Res. 2013, 101, 482-491. [CrossRef]

32. Bonito, M.C.; Cicala, C.; Marcotullio, M.C.; Maione, F.; Mascolo, N. Biological activity of bicyclic and tricyclic diterpenoids from Salvia species of immediate pharmacological and pharmaceutical interest. Nat. Prod. Commun. 2011, 6, 1205-1215. [CrossRef]

33. Vilahur, G.; Badimon, L. Antiplatelet properties of natural products. Vascul. Pharmacol. 2013, 59, 67-75. [CrossRef]

34. Maione, F.; Cicala, C.; Musciacco, G.; De Feo, V.; Amat, A.G.; Ialenti, A.; Mascolo, N. Phenols, alkaloids and terpenes from medicinal plants with antihypertensive and vasorelaxant activities. A review of natural products as leads to potential therapeutic agents. Nat. Prod. Commun. 2013, 8, 1934578X1300800434. [CrossRef]

35. Wang, X.; Morris-Natschke, S.L.; Lee, K.-H. New developments in the chemistry and biology of the bioactive constituents of tanshen. Med. Res. Rev. 2007, 27, 133-148. [CrossRef] [PubMed]

36. Gao, S.; Liu, Z.; Li, H.; Little, P.J.; Liu, P.; Xu, S. Cardiovascular actions and therapeutic potential of tanshinone IIA. Atherosclerosis 2012, 220, 3-10. [CrossRef] [PubMed]

37. Maione, F.; De Feo, V.; Caiazzo, E.; De Martino, L.; Cicala, C.; Mascolo, N. Tanshinone IIA, a major component of Salvia milthorriza Bunge, inhibits platelet activation via Erk-2 signaling pathway. J. Ethnopharmacol. 2014, 155, 1236-1242. [CrossRef]

38. Maione, F.; Cantone, V.; Chini, M.G.; De Feo, V.; Mascolo, N.; Bifulco, G. Molecular mechanism of tanshinone IIA and cryptotanshinone in platelet anti-aggregating effects: An integrated study of pharmacology and computational analysis. Fitoterapia 2015, 100, 174-178. [CrossRef] [PubMed]

39. Schrödinger Release 2020-1: Maestro; Schrödinger, LLC.: New York, NY, USA, 2020.

40. Schrödinger Release 2020-1: LigPrep; Schrödinger, LLC.: New York, NY, USA, 2020.

41. Berman, H.M.; Westbrook, J.; Feng, Z.; Gilliland, G.; Bhat, T.N.; Weissig, H.; Shindyalov, I.N.; Bourne, P.E. The Protein Data Bank. Nucleic Acids Res. 2000, 28, 235-242. [CrossRef]

42. Lee, L.K.; Bryant, K.J.; Bouveret, R.; Lei, P.-W.; Duff, A.P.; Harrop, S.J.; Huang, E.P.; Harvey, R.P.; Gelb, M.H.; Gray, P.P.; et al Selective inhibition of human group IIA-secreted phospholipase A2 (hGIIA) signaling reveals arachidonic acid metabolism is associated with colocalization of hGIIA to vimentin in rheumatoid synoviocytes. J. Biol. Chem. 2013, 288, 15269-15279. [CrossRef]

43. Rimon, G.; Sidhu, R.S.; Lauver, D.A.; Lee, J.Y.; Sharma, N.P.; Yuan, C.; Frieler, R.A.; Trievel, R.C.; Lucchesi, B.R.; Smith, W.L. Coxibs interfere with the action of aspirin by binding tightly to one monomer of cyclooxygenase-1. Proc. Natl. Acad. Sci. USA 2010, 107, 28-33. [CrossRef]

44. Orlando, B.J.; Malkowski, M.G. Crystal structure of rofecoxib bound to human cyclooxygenase-2. Acta Crystallogr. Sect. F Struct. Biol. Cryst. Commun. 2016, 72, 772-776. [CrossRef]

45. Gilbert, N.C.; Bartlett, S.G.; Waight, M.T.; Neau, D.B.; Boeglin, W.E.; Brash, A.R.; Newcomer, M.E. The structure of human 5-lipoxygenase. Science 2011, 331, 217-219. [CrossRef]

46. Kuklish, S.L.; Antonysamy, S.; Bhattachar, S.N.; Chandrasekhar, S.; Fisher, M.J.; Fretland, A.J.; Gooding, K.; Harvey, A.; Hughes, N.E.; Luz, J.G.; et al. Characterization of 3,3-dimethyl substituted N-aryl piperidines as potent microsomal prostaglandin E synthase-1 inhibitors. Bioorg. Med. Chem. Lett. 2016, 26, 4824-4828. [CrossRef]

47. Cao, C.; Tan, Q.; Xu, C.; He, L.; Yang, L.; Zhou, Y.; Zhou, Y.; Qiao, A.; Lu, M.; Yi, C.; et al. Structural basis for signal recognition and transduction by platelet-activating-factor receptor. Nat. Struct. Mol. Biol. 2018, 25, 488-495. [CrossRef]

48. Morimoto, K.; Suno, R.; Hotta, Y.; Yamashita, K.; Hirata, K.; Yamamoto, M.; Narumiya, S.; Iwata, S.; Kobayashi, T. Crystal structure of the endogenous agonist-bound prostanoid receptor EP3. Nat. Chem. Biol. 2019, 15, 8-10. [CrossRef]

49. Toyoda, Y.; Morimoto, K.; Suno, R.; Horita, S.; Yamashita, K.; Hirata, K.; Sekiguchi, Y.; Yasuda, S.; Shiroishi, M.; Shimizu, T.; et al. Ligand binding to human prostaglandin E receptor EP4 at the lipid-bilayer interface. Nat. Chem. Biol. 2019, 15, 18-26. [CrossRef]

50. Lovejoy, B.; Welch, A.R.; Carr, S.; Luong, C.; Broka, C.; Hendricks, R.T.; Campbell, J.A.; Walker, K.A.M.; Martin, R.; Van Wart, H.; et al. Crystal structures of MMP-1 and -13 reveal the structural basis for selectivity of collagenase inhibitors. Nat. Struct. Biol. 1999, 6, 217-221. [PubMed]

51. Feng, Y.; Likos, J.J.; Zhu, L.; Woodward, H.; Munie, G.; McDonald, J.J.; Stevens, A.M.; Howard, C.P.; De Crescenzo, G.A.; Welsch, D.; et al. Solution structure and backbone dynamics of the catalytic domain of matrix metalloproteinase- 2 complexed with a hydroxamic acid inhibitor. Biochim. Biophys. Acta 2002, 1598, 10-23. [CrossRef] 
52. Madhavi Sastry, G.; Adzhigirey, M.; Day, T.; Annabhimoju, R.; Sherman, W. Protein and ligand preparation: Parameters, protocols, and influence on virtual screening enrichments. J. Comput. Aided Mol. Des. 2013, 27, 221-234. [CrossRef]

53. Raucci, F.; Mansour, A.A.; Casillo, G.M.; Saviano, A.; Caso, F.; Scarpa, R.; Mascolo, N.; Iqbal, A.J.; Maione, F. Interleukin-17A (IL-17A), a key molecule of innate and adaptive immunity, and its potential involvement in COVID-19-related thrombotic and vascular mechanisms. Autoimmun. Rev. 2020, 19, 102572. [CrossRef] [PubMed]

54. Maione, F.; Cantone, V.; Pace, S.; Chini, M.G.; Bisio, A.; Romussi, G.; Pieretti, S.; Werz, O.; Koeberle, A.; Mascolo, N.; et al. Anti-inflammatory and analgesic activity of carnosol and carnosic acid in vivo and in vitro and in silico analysis of their target interactions. Br. J. Pharmacol. 2017, 174, 1497-1508. [CrossRef] [PubMed]

55. Friesner, R.A.; Banks, J.L.; Murphy, R.B.; Halgren, T.A.; Klicic, J.J.; Mainz, D.T.; Repasky, M.P.; Knoll, E.H.; Shelley, M.; Perry, J.K.; et al. Glide: A new approach for rapid, accurate docking and scoring. 1. Method and assessment of docking accuracy. J. Med. Chem. 2004, 47, 1739-1749. [CrossRef]

56. Friesner, R.A.; Murphy, R.B.; Repasky, M.P.; Frye, L.L.; Greenwood, J.R.; Halgren, T.A.; Sanschagrin, P.C.; Mainz, D.T. Extra precision glide: Docking and scoring incorporating a model of hydrophobic enclosure for protein-ligand complexes. J. Med. Chem. 2006, 49, 6177-6196. [CrossRef]

57. Halgren, T.A.; Murphy, R.B.; Friesner, R.A.; Beard, H.S.; Frye, L.L.; Pollard, W.T.; Banks, J.L. Glide: A new approach for rapid, accurate docking and scoring. 2. Enrichment factors in database screening. J. Med. Chem. 2004, 47, 1750-1759. [CrossRef] [PubMed]

58. Schrödinger Release 2020-1: Glide; Schrödinger, LLC.: New York, NY, USA, 2020.

59. Farid, R.; Day, T.; Friesner, R.A.; Pearlstein, R.A. New insights about HERG blockade obtained from protein modeling, potential energy mapping, and docking studies. Biorg. Med. Chem. 2006, 14, 3160-3173. [CrossRef] [PubMed]

60. Sherman, W.; Beard, H.S.; Farid, R. Use of an Induced Fit Receptor Structure in Virtual Screening. Chem. Biol. Drug Des. 2006, 67, 83-84. [CrossRef] [PubMed]

61. Sherman, W.; Day, T.; Jacobson, M.P.; Friesner, R.A.; Farid, R. Novel Procedure for Modeling Ligand/Receptor Induced Fit Effects. J. Med. Chem. 2006, 49, 534-553. [CrossRef]

62. Schrödinger Release 2020-1: Induced Fit. Docking Protocol; Glide, Schrödinger, LLC.: New York, NY, USA, 2016; Prime, Schrödinger, LLC.: New York, NY, USA, 2020.

63. Steinhilber, D.; Hofmann, B. Recent advances in the search for novel 5-lipoxygenase inhibitors. Basic Clin. Pharmacol. Toxicol. 2014, 114, 70-77. [CrossRef]

64. Koeberle, A.; Siemoneit, U.; Bühring, U.; Northoff, H.; Laufer, S.; Albrecht, W.; Werz, O. Licofelone suppresses prostaglandin E2 formation by interference with the inducible microsomal prostaglandin E2 Synthase-1. J. Pharmacol. Exp. Ther. 2008, $326,975$. [CrossRef] [PubMed]

65. Lauro, G.; Cantone, V.; Potenza, M.; Fischer, K.; Koeberle, A.; Werz, O.; Riccio, R.; Bifulco, G. Discovery of 3-hydroxy-3pyrrolin-2-one-based mPGES-1 inhibitors using a multi-step virtual screening protocol. MedChemComm 2018, 9, $2028-2036$. [CrossRef]

66. Fischer, L.; Szellas, D.; Rådmark, O.; Steinhilber, D.; Werz, O. Phosphorylation- and stimulus-dependent inhibition of cellular 5-lipoxygenase activity by nonredox-type inhibitors. FASEB J. 2003, 17, 1-24. [CrossRef]

67. Pace, S.; Zhang, K.; Jordan, P.M.; Bilancia, R.; Wang, W.; Börner, F.; Hofstetter, R.K.; Potenza, M.; Kretzer, C.; Gerstmeier, J.; et al. Anti-inflammatory celastrol promotes a switch from leukotriene biosynthesis to formation of specialized pro-resolving lipid mediators. Pharmacol. Res. 2021, 167, 105556. [CrossRef] [PubMed]

68. Siemoneit, U.; Hofmann, B.; Kather, N.; Lamkemeyer, T.; Madlung, J.; Franke, L.; Schneider, G.; Jauch, J.; Poeckel, D.; Werz, O. Identification and functional analysis of cyclooxygenase- 1 as a molecular target of boswellic acids. Biochem. Pharmacol. 2008, 75, 503-513. [CrossRef]

69. Kilkenny, C.; Browne, W.; Cuthill, I.C.; Emerson, M.; Altman, D.G.; Group, N.C.R.R.G.W. Animal research: Reporting in vivo experiments: The ARRIVE guidelines. Br. J. Pharmacol. 2010, 160, 1577-1579. [CrossRef]

70. McGrath, J.C.; Lilley, E. Implementing guidelines on reporting research using animals (ARRIVE etc.): New requirements for publication in BJP. Br. J. Pharmacol. 2015, 172, 3189-3193. [CrossRef]

71. Bowie, E.J.; Owen, J.C.A. The bleeding time. Prog. Hemost. Thromb. 1974, 2, 249-271. [PubMed]

72. Law, D.A.; DeGuzman, F.R.; Heiser, P.; Ministri-Madrid, K.; Killeen, N.; Phillips, D.R. Integrin cytoplasmic tyrosine motif is required for outside-in $\alpha \mathrm{IIb} \beta 3$ signalling and platelet function. Nature 1999, 401, 808-811. [CrossRef]

73. Tucker, K.L.; Sage, T.; Gibbins, J.M. Clot Retraction. In Platelets and Megakaryocytes: Volume 3, Additional Protocols and Perspectives; Gibbins, J.M., Mahaut-Smith, M.P., Eds.; Springer New York: New York, NY, USA, 2012; pp. 101-107.

74. Raucci, F.; Saviano, A.; Casillo, G.M.; Guerra-Rodriguez, M.; Mansour, A.A.; Piccolo, M.; Ferraro, M.G.; Panza, E.; Vellecco, V.; Irace, C.; et al. IL-17-induced inflammation modulates the mPGES-1/PPAR- $\gamma$ pathway in monocytes/macrophages. Br. J. Pharmacol. 2021, 2021, 1-17. [CrossRef] [PubMed]

75. Saviano, A.; Casillo, G.M.; Raucci, F.; Pernice, A.; Santarcangelo, C.; Piccolo, M.; Ferraro, M.G.; Ciccone, M.; Sgherbini, A.; Pedretti, N.; et al. Supplementation with ribonucleotide-based ingredient (Ribodiet ${ }^{\circledR}$ ) lessens oxidative stress, brain inflammation, and amyloid pathology in a murine model of Alzheimer. Biomed. Pharmacother. 2021, 139, 111579. [CrossRef] 
76. Curtis, M.J.; Alexander, S.; Cirino, G.; Docherty, J.R.; George, C.H.; Giembycz, M.A.; Hoyer, D.; Insel, P.A.; Izzo, A.A.; Ji, Y.; et al. Experimental design and analysis and their reporting II: Updated and simplified guidance for authors and peer reviewers. Br. J. Pharmacol. 2018, 175, 987-993. [CrossRef]

77. Alexander, S.P.H.; Roberts, R.E.; Broughton, B.R.S.; Sobey, C.G.; George, C.H.; Stanford, S.C.; Cirino, G.; Docherty, J.R.; Giembycz, M.A.; Hoyer, D.; et al. Goals and practicalities of immunoblotting and immunohistochemistry: A guide for submission to the British Journal of Pharmacology. Br. J. Pharmacol. 2018, 175, 407-411. [CrossRef]

78. George, C.H.; Stanford, S.C.; Alexander, S.; Cirino, G.; Docherty, J.R.; Giembycz, M.A.; Hoyer, D.; Insel, P.A.; Izzo, A.A.; Ji, Y.; et al Updating the guidelines for data transparency in the British Journal of Pharmacology-Data sharing and the use of scatter plots instead of bar charts. Br. J. Pharmacol. 2017, 174, 2801-2804. [CrossRef] [PubMed]

79. Dong, Y.; Morris-Natschke, S.L.; Lee, K.-H. Biosynthesis, total syntheses, and antitumor activity of tanshinones and their analogs as potential therapeutic agents. Nat. Prod. Rep. 2011, 28, 529-542. [CrossRef] [PubMed]

80. Burley, S.K.; Berman, H.M.; Bhikadiya, C.; Bi, C.; Chen, L.; Di Costanzo, L.; Christie, C.; Dalenberg, K.; Duarte, J.M.; Dutta, S.; et al RCSB Protein Data Bank: Biological macromolecular structures enabling research and education in fundamental biology, biomedicine, biotechnology and energy. Nucleic Acids Res. 2018, 47, D464-D474. [CrossRef]

81. Schrödinger Release 2020-1: Protein Preparation Wizard; Schrödinger, LLC.: New York, NY, USA, 2020.

82. Chini, M.G.; De Simone, R.; Bruno, I.; Riccio, R.; Dehm, F.; Weinigel, C.; Barz, D.; Werz, O.; Bifulco, G. Design and synthesis of a second series of triazole-based compounds as potent dual mPGES-1 and 5-lipoxygenase inhibitors. Eur. J. Med. Chem. 2012, 54, 311-323. [CrossRef] [PubMed]

83. Moy, F.J.; Chanda, P.K.; Chen, J.M.; Cosmi, S.; Edris, W.; Skotnicki, J.S.; Wilhelm, J.; Powers, R. NMR solution structure of the catalytic fragment of human fibroblast collagenase complexed with a sulfonamide derivative of a hydroxamic acid compound. Biochemistry 1999, 38, 7085-7096. [CrossRef]

84. Llorens, O.; Perez, J.J.; Palomer, A.; Mauleon, D. Differential binding mode of diverse cyclooxygenase inhibitors. J. Mol. Graph. Modell. 2002, 20, 359-371. [CrossRef]

85. Reddy, K.K.; Vidya Rajan, V.K.; Gupta, A.; Aparoy, P.; Reddanna, P. Exploration of binding site pattern in arachidonic acid metabolizing enzymes, Cyclooxygenases and Lipoxygenases. BMC Res. Notes 2015, 8, 152. [CrossRef]

86. Terracciano, S.; Lauro, G.; Strocchia, M.; Fischer, K.; Werz, O.; Riccio, R.; Bruno, I.; Bifulco, G. Structural insights for the optimization of dihydropyrimidin-2(1H)-one based mPGES-1 inhibitors. ACS Med. Chem. Lett. 2015, 6, 187-191. [CrossRef]

87. Giordanetto, F.; Pettersen, D.; Starke, I.; Nordberg, P.; Dahlström, M.; Knerr, L.; Selmi, N.; Rosengren, B.; Larsson, L.-O.; Sandmark, J.; et al. Discovery of AZD2716: A novel secreted phospholipase A2 (sPLA2) inhibitor for the treatment of coronary artery disease. ACS Med. Chem. Lett. 2016, 7, 884-889. [CrossRef]

88. Hou, S.; Xu, T.; Xu, J.; Qu, L.; Xu, Y.; Chen, L.; Liu, J. Structural basis for functional selectivity and ligand recognition revealed by crystal structures of human secreted phospholipase A2 group IIE. Sci. Rep. 2017, 7, 10815. [CrossRef]

89. Potenza, M.; Sciarretta, M.; Chini, M.G.; Saviano, A.; Maione, F.; D'Auria, M.V.; De Marino, S.; Giordano, A.; Hofstetter, R.K.; Festa, C.; et al. Structure-based screening for the discovery of 1,2,4-oxadiazoles as promising hits for the development of new anti-inflammatory agents interfering with eicosanoid biosynthesis pathways. Eur. J. Med. Chem. 2021, 224, 113693. [CrossRef] [PubMed]

90. Lauro, G.; Terracciano, S.; Cantone, V.; Ruggiero, D.; Fischer, K.; Pace, S.; Werz, O.; Bruno, I.; Bifulco, G. A combinatorial virtual screening approach driving the synthesis of 2,4-thiazolidinedione-based molecules as new sual mPGES-1/5-LO inhibitors. ChemMedChem 2020, 15, 481-489. [CrossRef]

91. Chini, M.G.; Ferroni, C.; Cantone, V.; Dambruoso, P.; Varchi, G.; Pepe, A.; Fischer, K.; Pergola, C.; Werz, O.; Bruno, I. Elucidating new structural features of the triazole scaffold for the development of mPGES-1 inhibitors. MedChemComm 2015, 6, 75-79. [CrossRef]

92. Oslund, R.C.; Gelb, M.H. Biochemical characterization of selective inhibitors of human group IIA secreted phospholipase A2 and hyaluronic acid-linked inhibitor conjugates. Biochemistry 2012, 51, 8617-8626. [CrossRef]

93. Ramirez, F.; Jain, M.K. Phospholipase A2 at the bilayer interface. Proteins Struct. Funct. Bioinform. 1991, 9, 229-239. [CrossRef]

94. Gierse, J.K.; McDonald, J.J.; Hauser, S.D.; Rangwala, S.H.; Koboldt, C.M.; Seibert, K. A single amino acid difference between cyclooxygenase-1 (COX-1) and -2 (COX-2) reverses the selectivity of COX-2 specific inhibitors. J. Biol. Chem. 1996, 271, 15810-15814. [CrossRef]

95. Blobaum, A.L.; Marnett, L.J. Structural and functional basis of cyclooxygenase inhibition. J. Med. Chem. 2007, 50, 1425-1441. [CrossRef] [PubMed]

96. Ermondi, G.; Caron, G.; Lawrence, R.; Longo, D. Docking studies on NSAID/COX-2 isozyme complexes using Contact Statistics analysis. J. Comput. Aided Mol. Des. 2004, 18, 683-696. [CrossRef]

97. Matheson, A.J.; Figgitt, D.P. Rofecoxib. Drugs 2001, 61, 833-865. [CrossRef] [PubMed]

98. McCormack, P.L. Celecoxib. Drugs 2011, 71, 2457-2489. [CrossRef]

99. Werz, O. 5-lipoxygenase: Cellular biology and molecular pharmacology. Curr. Drug Targets Inflamm. Allergy 2002, 1, 23-44. [CrossRef] [PubMed]

100. Pergola, C.; Werz, O. 5-Lipoxygenase inhibitors: A review of recent developments and patents. Expert Opin. Ther. Pat. 2010, 20, 355-375. [CrossRef] [PubMed] 
101. Koeberle, A.; Werz, O. Natural products as inhibitors of prostaglandin $\mathrm{E}_{2}$ and pro-inflammatory 5-lipoxygenase-derived lipid mediator biosynthesis. Biotechnol. Adv. 2018, 36, 1709-1723. [CrossRef] [PubMed]

102. Newcomer, M.E.; Brash, A.R. The structural basis for specificity in lipoxygenase catalysis. Protein Sci. 2015, 24, 298-309. [CrossRef]

103. Lauro, G.; Manfra, M.; Pedatella, S.; Fischer, K.; Cantone, V.; Terracciano, S.; Bertamino, A.; Ostacolo, C.; Gomez-Monterrey, I.; De Nisco, M.; et al. Identification of novel microsomal prostaglandin E2 synthase-1 (mPGES-1) lead inhibitors from Fragment Virtual Screening. Eur. J. Med. Chem. 2017, 125, 278-287. [CrossRef] [PubMed]

104. Toscano, E.C.D.B.; Silva, B.C.; Victoria, E.C.G.; Cardoso, A.C.D.S.; Miranda, A.S.D.; Sugimoto, M.A.; Sousa, L.P.; Carvalho, B.A.D.; Kangussu, L.M.; Silva, D.G.D.; et al. Platelet-activating factor receptor (PAFR) plays a crucial role in experimental global cerebral ischemia and reperfusion. Brain Res. Bull. 2016, 124, 55-61. [CrossRef] [PubMed]

105. Yao, C.; Sakata, D.; Esaki, Y.; Li, Y.; Matsuoka, T.; Kuroiwa, K.; Sugimoto, Y.; Narumiya, S. Prostaglandin E2-EP4 signaling promotes immune inflammation through TH1 cell differentiation and TH17 cell expansion. Nat. Med. 2009, 15, 633-640. [CrossRef]

106. Liu, Y.; Jennings, N.L.; Dart, A.M.; Du, X.J. Standardizing a simpler, more sensitive and accurate tail bleeding assay in mice. World J. Exp. Med. 2012, 2, 30-36. [CrossRef]

107. Cicala, C.; Cirino, G. Linkage between inflammation and coagulation: An update on the molecular basis of the crosstalk. Life Sci. 1998, 62, 1817-1824. [CrossRef]

108. Jurado, R.; Ribeiro, M. Possible role of systemic inflammatory reaction in vascular access thrombosis. South. Med. J. 1999, 92, 877-881. [CrossRef]

109. Cicala, C.; Morello, S.; Alfieri, A.; Vellecco, V.; Marzocco, S.; Autore, G. Haemostatic imbalance following carrageenan-induced rat paw oedema. Eur. J. Pharmacol. 2007, 577, 156-161. [CrossRef] [PubMed]

110. Lindemann, S.; Tolley, N.D.; Dixon, D.A.; McIntyre, T.M.; Prescott, S.M.; Zimmerman, G.A.; Weyrich, A.S. Activated platelets mediate inflammatory signaling by regulated interleukin 1beta synthesis. J. Cell Biol. 2001, 154, 485-490. [CrossRef]

111. Ruggeri, Z.M. Platelet interactions with vessel wall components during thrombogenesis. Blood Cells Mol. Dis. 2006, 36, 145-147. [CrossRef] [PubMed]

112. Koupenova, M.; Clancy, L.; Corkrey Heather, A.; Freedman Jane, E. Circulating platelets as mediators of immunity, inflammation, and thrombosis. Circul. Res. 2018, 122, 337-351. [CrossRef]

113. Margraf, A.; Zarbock, A. Platelets in inflammation and resolution. J. Immunol. 2019, 203, 2357. [CrossRef]

114. Wang, M.; Fitzgerald, G.A. Cardiovascular biology of microsomal prostaglandin E synthase-1. Trends Cardiovasc. Med. 2010, 20, 189-195. [CrossRef] [PubMed]

115. Chen, L.; Yang, G.; Monslow, J.; Todd, L.; Cormode, D.P.; Tang, J.; Grant, G.R.; DeLong, J.H.; Tang, S.Y.; Lawson, J.A.; et al. Myeloid cell microsomal prostaglandin E synthase-1 fosters atherogenesis in mice. Proc. Natl. Acad. Sci. USA 2014, $111,6828$. [CrossRef]

116. Wang, M.; Lee, E.; Song, W.; Ricciotti, E.; Rader Daniel, J.; Lawson John, A.; Puré, E.; FitzGerald Garret, A. Microsomal prostaglandin E synthase-1 deletion suppresses oxidative stress and angiotensin II-induced abdominal aortic aneurysm formation. Circulation 2008, 117, 1302-1309. [CrossRef]

117. Wang, M.; Zukas, A.M.; Hui, Y.; Ricciotti, E.; Puré, E.; FitzGerald, G.A. Deletion of microsomal prostaglandin E synthase-1 augments prostacyclin and retards atherogenesis. Proc. Natl. Acad. Sci. USA 2006, 103, 14507. [CrossRef]

118. Cheng, Y.; Wang, M.; Yu, Y.; Lawson, J.; Funk, C.D.; FitzGerald, G.A. Cyclooxygenases, microsomal prostaglandin E synthase-1, and cardiovascular function. J. Clin. Invest. 2006, 116, 1391-1399. [CrossRef]

119. Chen, L.; Yang, G.; Xu, X.; Grant, G.; Lawson John, A.; Bohlooly, Y.M.; FitzGerald Garret, A. Cell selective cardiovascular biology of microsomal prostaglandin E synthase-1. Circulation 2013, 127, 233-243. [CrossRef] [PubMed]

120. Bergmeier, W.; Piffath, C.L.; Goerge, T.; Cifuni, S.M.; Ruggeri, Z.M.; Ware, J.; Wagner, D.D. The role of platelet adhesion receptor GPIb $\alpha$ far exceeds that of its main ligand, von Willebrand factor, in arterial thrombosis. Proc. Natl. Acad. Sci. USA 2006, 103, 16900-16905. [CrossRef]

121. Patrignani, P.; Tacconelli, S.; Capone, M.L. Risk management profile of etoricoxib: An example of personalized medicine. Ther. Clin. Risk Manag. 2008, 4, 983-997. [CrossRef]

122. Gross, S.; Tilly, P.; Hentsch, D.; Vonesch, J.-L.; Fabre, J.-E. Vascular wall-produced prostaglandin E2 exacerbates arterial thrombosis and atherothrombosis through platelet EP3 receptors. J. Exp. Med. 2007, 204, 311-320. [CrossRef]

123. Heptinstall, S.; Espinosa, D.I.; Manolopoulos, P.; Glenn, J.R.; White, A.E.; Johnson, A.; Dovlatova, N.; Fox, S.C.; May, J.A.; Hermann, D.; et al. DG-041 inhibits the EP3 prostanoid receptor-A new target for inhibition of platelet function in atherothrombotic disease. Platelets 2008, 19, 605-613. [CrossRef]

124. Kuriyama, S.; Kashiwagi, H.; Yuhki, K.-I.; Kojima, F.; Yamada, T.; Fujino, T.; Hara, A.; Takayama, K.; Maruyama, T.; Yoshida, A.; et al. Selective activation of the prostaglandin E2 receptor subtype EP2 or EP4 leads to inhibition of platelet aggregation. Thromb. Haemost. 2010, 104, 796-803. [PubMed]

125. Guo, R.; Li, L.; Su, J.; Li, S.; Duncan, S.E.; Liu, Z.; Fan, G. Pharmacological activity and mechanism of Tanshinone IIA in related diseases. Drug Des. Devel. Ther. 2020, 14, 4735-4748. [CrossRef] [PubMed]

126. Hur, J.M.; Shim, J.S.; Jung, H.J.; Kwon, H.J. Cryptotanshinone but not tanshinone IIA inhibits angiogenesis in vitro. Exp. Mol. Med. 2005, 37, 133-137. [CrossRef] [PubMed] 
127. Wang, M.; Liu, J.; Zhou, B.; Xu, R.; Tao, L.; Ji, M.; Zhu, L.; Jiang, J.; Shen, J.; Gui, X.; et al. Acute and sub-chronic toxicity studies of Danshen injection in Sprague-Dawley rats. J. Ethnopharmacol. 2012, 141, 96-103. [CrossRef]

128. Chiu, T.-L.; Su, C.-C. Tanshinone IIA induces apoptosis in human lung cancer A549 cells through the induction of reactive oxygen species and decreasing the mitochondrial membrane potential. Int. J. Mol. Med. 2010, 25, 231-236.

129. Lee, W.Y.W.; Chiu, L.C.M.; Yeung, J.H.K. Cytotoxicity of major tanshinones isolated from Danshen (Salvia miltiorrhiza) on HepG2 cells in relation to glutathione perturbation. Food Chem. Toxicol. 2008, 46, 328-338. [CrossRef] [PubMed]

130. Mosaddik, M.A. In vitro cytotoxicity of Tanshinones isolated from Salvia miltiorrhiza Bunge against P388 lymphocytic leukemia cells. Phytomedicine 2003, 10, 682-685. [CrossRef] [PubMed] 